Aus dem Institut für Medizinische Mikrobiologie

(Prof. Dr. med. U. Groß)

im Zentrum Hygiene und Humangenetik

der Medizinischen Fakultät der Universität Göttingen

\title{
Vergleichende Untersuchungen der Nasenflora von Probanden aus Ghana und Deutschland.
}

INAUGURAL-DISSERTATION

zur Erlangung des Doktorgrades

der Medizinischen Fakultät der

Georg-August-Universität zu Göttingen

\author{
vorgelegt von \\ Hannah Seeba
}

aus

Bremen

Göttingen 2015 
Dekan: $\quad$ Prof. Dr. rer. nat. H. K. Kroemer

I. Berichterstatter/in: Prof. Dr. med. U. Groß

II. Berichterstatter/in: Prof. Dr. R. Laskawi

III. Berichterstatter/in: Prof. Dr. M. Schön

Tag der mündlichen Prüfung: 12.08.2015 um 11.00 Uhr 


\section{Inhaltsverzeichnis}

Inhaltsverzeichnis 1

Abbildungsverzeichnis $\quad 2$

Abkürzungsverzeichnis 3

1. Einleitung 4

1.1. Einführung 4

1.2. Problemstellung $r$

1.3. Bedeutung von MRSA 11

$\begin{array}{lr}\text { 1.4. } & \text { Fragestellungen } \\ & 12\end{array}$

2. Experimenteller Teil - Patienten und Methoden 13

2.1 Probanden 13

2.1.1 Patienten in Ghana 14

2.1.2 Probanden in Deutschland $\quad 15$

2.1.3 Fragebogen 15

2.2 Methoden 16

2.2.1 Bakterienanzucht 16

2.2.2 Differenzierung 17

2.2.3 Erstellen der Antibiogramme 19

$\begin{array}{lll}2.3 & \text { Statistik } & 19\end{array}$

$\begin{array}{lr}\text { 3. Ergebnisse } & \mathbf{2 0}\end{array}$

3.1 Die Zusammensetzung der nasalen Bakterienflora 20

3.2 Die Resistenzlage 24

3.3 Konkordanz zwischen der Anwendung von
Antibiotika und Resistenzen

3.4 MRSA im Vergleich Ghana - Deutschland 30

3.5 Fakultative Pathogenität des nasalen Bakterieneservoirs 31

4. Diskussion $\quad 35$

$\begin{array}{ll}\text { 5. Zusammenfassung } & 49\end{array}$

6. Literaturverzeichnis $\quad \mathbf{5 0}$ 


\section{Abbildungsverzeichnis}

Abb. 1 Geschlechterverteilung der Probanden in Ghana und Deutschland 13

Abb. 2 Altersverteilung der Probanden Ghana - Deutschland 14

Abb. 3 Verteilung der apathogenen Flora in Nasenabstrichen von ghanaischen und deutschen Probanden

Abb. 4 Weitere Mikroorganismen, für diese Studie nicht relevant, im Vergleich der Nasenabstriche ghanaischer und deutscher Probanden

Abb. 5 Verteilung der fakultativ pathogenen Keime aus Nasenabstrichen ghanaischer und deutscher Probanden

Abb. 6 Signifikante Unterschiede in den Resistenzraten der Koagulasenegativen Staphylokokken im Vergleich der Abstriche von Probanden aus Ghana und Deutschland

Abb. 7 Komplettes Antibiogramm Koagulase-negativer Staphylokokken im Vergleich der Abstriche aus Ghana und Deutschland

Abb. 8 Resistenzraten von S. aureus in \% im Vergleich der Abstriche von Probanden aus Ghana und Deutschland

Abb. 9 Resistenzraten der Enterobacteriaceae im Vergleich der Abstriche von Probanden aus Ghana und Deutschland

Abb.10 Resistenzraten von Pseudomonas/Stenotrophomonas im Vergleich der Abstriche von Probanden aus Ghana und Deutschland

Abb.11 Resistenzraten von Enterococcus faecalis im Vergleich der Abstriche von Probanden aus Ghana und Deutschland

Abb.12 Art der Antibiotika, die von ghanaischen Probanden innerhalb der letzten 4 Wochen vor Probeentnahme eingenommen wurden

Abb.13 Signifikante Unterschiede der Chloramphenicol-Resistenzen im Vergleich der Flora der Abstriche aus Ghana und Deutschland

Abb.14 Prozentuale Verteilung der Gründe, die zur Vorstellung in der Poliklinik führten (Mehrfachnennungen möglich)

Abb.15 Krankheiten der deutschen Probanden innerhalb des Jahres vor Probeentnahme

Abb.16 Tropenaufenthalte der deutschen Probanden vor Entnahme des Abstriches 


\section{Abkürzungsverzeichnis}

ESBL

KNS

MRSA

NDM

VRE

spp

Ampi/Amoxi extended spectrum $\beta$-lactamase

Koagulase-negative Staphylokokken, z.B. S. epidermidis

Methicillin/Oxacillin-resistenter S. aureus, gleichbedeutend mit ORSA

Neu Delhi Metalloprotease

Vancomycin-resistenter Enterokokkus

Spezies (Plural)

Ampicillin/Amoxicillin 


\section{Einleitung}

\section{$1.1 \quad$ Einführung}

Die vorliegende Arbeit stellt einen Vergleich zwischen der nasalen Bakterienbesiedlung und den jeweiligen Antibiotikaresistenzen dieser Flora bei 200 ghanaischen Patienten und einer deutschen Kontrollgruppe an.

Von Natur aus ist der menschliche Körper von Bakterien besiedelt, die ihn gegen Krankheiten schützen können, während er ihnen einen optimalen Lebensraum bietet. Auf diese Weise entsteht eine Symbiose, solange die bakterielle Besiedlung und die Immunlage des Menschen stabil bleiben.

Die normale bakterielle Nasenflora besteht aus Koagulase-negativen Staphylokokken (KNS), Viridans-Streptokokken, coryneformen Bakterien und Neisserien sowie einigen anderen Bakterienarten (z.B.: Micrococcus, Stomatococcus, Haemophilus parainfluenzae, Veillonella, Fusobakterium etc.) (Glück und Gebbers 2003), die jedoch in dieser Studie weniger Relevanz haben.

Vielfältige exogene Faktoren (wie z.B. Nahrung, Alter, Stress, Wasserversorgung und die Verschmutzung der Luft) haben Einfluss auf die Zusammensetzung der natürlichen Flora.

Bis zu 30\% der Bevölkerung sind permanente Träger von Staphylococcus aureus und solange sie immunkompetent sind und keine größeren Haut- oder Schleimhautläsionen aufweisen, bleibt diese Besiedlung zumeist ohne infektiologische Folgen. 60\% der Menschen sind zeitweise mit S. aureus besiedelt und nur 20\% sind nie Träger von S. aureus (Foster 2004). Eine Staphylokokken-Bakteriämie, ausgehend von einer lokalen Besiedlung, kann ohne adäquate Antibiotikatherapie tödlich verlaufen, besonders wenn es sich um Keime mit multiplen Antibiotikaresistenzen handelt.

Besonders in den Ländern des Südens führen Infektionen überproportional häufig zu Krankheit und Tod. Immer wieder brechen Epidemien - wie aktuell z.B. Ebola - aus, die aufgrund mangelnder Hygiene und Ressourcen kaum in den Griff zu bekommen sind. Aber auch durch Mangelernährung, fehlende medizinische Versorgung sowie Impfdefizite sind Infektionskrankheiten in den ärmeren Ländern die Haupttodesursache in allen Altersklassen (Ako-Nai et al. 1991). 
Laut WHO starben im Jahr 2012 weltweit 6,55 Millionen Kinder unter 5 Jahren, davon 3,16 Millionen im subsaharischen Afrika. Das bedeutet, dass von 1000 lebend geborenen Kindern 98 vor dem Erreichen des 5. Lebensjahres versterben (WHO Child Mortality 2013). Mehr als die Hälfte der Todesfälle wurde durch Erkrankungen oder Umstände verursacht, die mit einfachen Methoden behandelbar oder zu verhindern gewesen wären. Die Mortalität von Kindern unter 5 Jahren ist in afrikanischen Ländern südlich der Sahara 16,5 Mal höher als bei Kindern in anderen Regionen. 70\% der Todesfälle im frühen Kindesalter treten in Ländern südlich der Sahara und in Südostasien auf. (WHO Child Mortality 2013). Die Haupttodesursachen bei unter 5-Jährigen sind Pneumonie (17\%), Komplikationen bei Frühgeburtlichkeit (15\%), perinatale Komplikationen (10\%), Durchfall (9\%) und Malaria (7\%). Global gesehen sind 45\% aller Todesfälle bei unter 5-Jährigen mit Mangelernährung in Verbindung zu bringen (WHO Child Mortality 2013).

1928 gelang ein entscheidender Durchbruch im Kampf gegen die mikrobielle Gefahr mit der Entdeckung des Penicillins durch A. Flemming. In den folgenden Jahren wurden weitere Antibiotika entwickelt, jedoch kann von einem Sieg gegen die Krankheitserreger keinesfalls die Rede sein (WHO Infectious Disease 2000).

Bereits 1939 wurde der erste Resistenzmechanismus gegen Penicillin zufällig bei Escherichia coli festgestellt, bei dem eine bakterielle Penicillase gefunden wurde. Damals maßen die Entdecker dem Problem jedoch keine besondere Aufmerksamkeit bei, da das Penicillin primär zur Bekämpfung von Staphylokokken und Streptokokken diente (Bonomo und Rossolini 2008). Bald darauf stellte man jedoch auch Resistenzmechanismen durch enzymatische Inaktivierung (z.B. B-Lactamase) sowie Modifikationen des Zielstruktur bzw. des Angriffspunktes der Antibiotika (z.B. der Topoisomerase oder der Ribosomen) fest (Bonomo und Rossolini 2008). In den 50er Jahren waren bereits viele Staphylokokken gegen die damals verfügbaren Antibiotika resistent und konnten nur durch die Entwicklung von Penicillinasefesten Antibiotika wie dem Methicillin eingedämmt werden (Fluckiger und Widmer 1999).

Unter Antibiotikagabe kann es sehr rasch zur Ausbreitung von Resistenzen kommen. Eine schnelle Übertragung von Resistenzen ist z.B. durch die Konjugation bzw. den Transfer von Plasmiden zwischen Bakterien unterschiedlicher Gattungen möglich (Anokbonggo et al. 2004, Okolo 1986, Shanahan et al. 1995).

Eine besondere Bedrohung besteht durch multiresistente Keime, die sich in der ganzen Welt ausbreiten, hervorgerufen unter anderem durch unüberlegten Einsatz von Antibiotika. In einer Studie von Mettler et al. wurde gezeigt, dass $22 \%$ der primär angewendeten Antibiotika in 
einem Schweizer Krankenhaus nicht die adäquate Therapie darstellten. In $31 \%$ wurden die Antibiotika im Verlauf umgestellt, davon war die Umstellung wiederum in $27 \%$ unangemessen. (Die häufigste Ursache für unangemessene Therapie war ein unnötig breites Spektrum der Antibiotika, in 26\% der Fälle waren die Antibiotika unwirksam gegen die nachgewiesenen Bakterien oder die Therapie wurde trotz negativen Erregernachweises fortgesetzt (Mettler et al. 2007).

In Südostasien waren zum Zeitpunkt der Studie 98\% aller Gonorrhoe-Erreger multiresistent (auch gegen Breitbandantibiotika wie Ciprofloxacin und Cephalosporine der dritten Generation), was die Ausbreitungsmöglichkeiten von HIV durch sexuellen Kontakt ebenfalls erhöht, da der AIDS-Erreger die vorgeschädigte Schleimhaut besser penetrieren kann (WHO Infectious Disease 2000).

Auch die Industrieländer sind vor der Ausbreitung multiresistenter Keime nicht gefeit: So breiten sich der Methicillin/Oxacillin-resistente S. aureus (MRSA), Vancomycin-resistente Enterokokken (VRE) und zunehmend extended spectrum $\beta$-lactamase produzierende Enterobacteriaceae (ESBL-Keime) immer mehr aus und werden vor allem in Krankenhäusern zur epidemiologischen Gefahr, insbesondere für immungeschwächte Patienten. Anfang 2012 hatten beispielsweise ESBL-bildende Klebsiella pneumoniae $\mathrm{zu}$ einem nosokomialen Ausbruch in der neonatalen Abteilung eines Bremer Krankenhauses geführt. Es waren sieben Frühgeborene erkrankt, von denen drei starben (BFR 2012). Die Säuglingsstation wurde daraufhin geschlossen. Multiresistente Keime sind für bis zu $60 \%$ aller in Krankenhäusern erworbenen Infektionen verantwortlich und bedeuten einen großen Aufwand an personellen, hygienischen und finanziellen Ressourcen (Geyid und Lemeneh 1991; Paterson et al. 2004). 2010 wurde eine neue globale Bedrohung durch Enterobacteriaceae deutlich, die die MetalloB-Lactamase NDM-1 tragen und gegen nahezu alle vefügbaren Antibiotika resistent sind. Meist waren diese B-Lactamasen plasmidcodiert und damit transferierbar. Diese Isolate wurden bereits in Indien, Pakistan und dem Vereinigten Königreich nachgewiesen (Kumarasamy et al. 2010). NMD-1 ist eine neue Breitspektrum-Carbapenemase, die sämtliche B-Lactame bis auf Aztreonam inaktivieren kann (Shakil et al. 2011). 2013 wurden auch in China E.coli-Isolate gefunden, die Träger von NMD-1 waren und bis auf Polymyxin auf alle getesteten Antibiotika resistent reagierten. Sie waren per Transformation und Plasmid-Konjugation auf andere E.coli-Stämme (EC600 und DH5alpha) transferierbar (Liu et al. 2013). Eine weitere Studie in Indien zeigte 2011 eine In-Vitro Sensibilität der isolierten NDM-1-tragenden E.coli-Bakterien lediglich auf Polymyxine und Glycycline, die jedoch ein 
zweifelhaftes Sicherheitsprofil besitzen. Die Autoren empfehlen, Mikroorganismen auf NDM-1 zu screenen (Charan et al. 2012).

\section{$1.2 \quad$ Problemstellung}

Kommt es zu einer Verschiebung des Gleichgewichtes der bakteriellen Flora, so dass z.B. eine fakultativ pathogene Bakterienart gegenüber anderen überwiegt, kann es zu infektiösen Erkrankungen kommen. Eine derartige Verschiebung kann unter anderem durch den Gebrauch von Antibiotika und durch exogene Umweltfaktoren bedingt sein. Die Nase kann als potentielles Reservoir für fakultativ pathogene Keime angesehen werden, die sich als opportunistische Erreger bei geschwächter Immunlage systemisch ausbreiten können (Archer und Climo 2001, Daschner und Schumpelick 2002, Echave et al. 2003, Glück und Gebbers 2003, Ndip et al. 1995, von Eiff et al. 2001).

Ziel dieser Arbeit war es, mögliche Unterschiede in der bakteriellen Flora der menschlichen Nase von Individuen aus Ghana und Deutschland zu untersuchen sowie ggf. vorhandene Antibiotikaresistenzen $\mathrm{zu}$ dokumentieren und $\mathrm{zu}$ analysieren. Hierzu wurden zwei Probandenkollektive gegenübergestellt: einerseits wurden Nasenabstriche von 200 Patienten aus Ghana ausgewertet, auf der anderen Seite wurden Nasenabstriche von 101 deutschen Probanden untersucht.

Die Untersuchung sollte Rückschlüsse darauf erlauben, ob durch die gehäufte Anwendung von bestimmten Antibiotika Resistenzen induziert werden. In Ghana und Deutschland werden für einige Infektionen unterschiedliche Antibiotika verabreicht. Eine besondere Rolle nimmt unter diesem Aspekt das Chloramphenicol ein, das in Deutschland wegen seiner gefürchteten Nebenwirkungen - wie aplastischen Blutschäden, Gray-Syndrom, Neuritiden u.a. (Brodt 2013) - seit vielen Jahren nur noch sehr selten zum Einsatz kommt, während es zum Untersuchungszeitpunkt in Ghana oft noch zu den Alltagsantibiotika zählte.

Der besondere Reiz der Arbeit besteht in dem Vergleich der nasalen Bakterienflora eines westafrikanischen Landes (am Beispiel des ländlichen Ghana) mit der Nasenflora deutscher Probanden als Repräsentanten der Bewohner von Industrienationen.

Es ist anzunehmen, dass verschiedenste Faktoren einen Einfluss auf die kommensale Bakterienflora sowie deren Resistenzverhalten ausüben. Es handelt sich dabei um soziale, regionale, kulturelle, wirtschaftliche, ernährungsbedingte, klimatische und vor allem medizinische und hygienische Aspekte (Felmingham et al. 1996, Harbarth et al. 2002, 
Hofmann 1990, Mackie et al. 1992, Okolo 1986, Shanahan et al. 1995, Shanahan et al. 1993). Die Lebensweisen, Wohnverhältnisse, vorherrschenden Erkrankungen sowie medizinische und medikamentöse Versorgung der Bewohner der beiden hier untersuchten Länder unterscheiden sich grundlegend. Andererseits zeigen Studien, dass verschiedene Aspekte der Globalisierung, wie z.B. das vermehrte und immer einfacher werdende Reisen sowie die zunehmende Migration, eine Verbreitung resistenter Bakterien begünstigen können und damit lokale Unterschiede überwunden werden (Kumarasamy et al. 2010).

Der Umgang mit Gesundheit im ländlichen Ghana ist nach wie vor stark durch Animismus und Spiritualität geprägt. Kräuterheiler und Priester stehen den Ärzten gegenüber, jedoch hat die traditionelle Heilkunde durch den wachsenden Einfluss der modernen sogenannten Schulmedizin an Ansehen und Prestige verloren (Alban et al. 2000).

Die medizinische Versorgung im ruralen Ghana basiert auf primären Gesundheitseinrichtungen wie einem Dorfgesundheitshelfer oder paramedizinischen Hilfskräften. Diese Art von Versorgung stellt für große Teile der Bevölkerung den einzigen Kontakt mit der Medizin dar. Nur ein minimaler Anteil der Bevölkerung hat Zugriff auf Fachärzte und Unikliniken oder nationale Krankenhäuser. In Deutschland standen 2013 für 100000 Einwohnern je 325-348 Ärzte und 681-799 Krankenschwestern und Hebammen zur Verfügung, in Ghana waren es 11-24 Ärzte und 98-109 Krankenschwestern und Hebammen (lokale Unterschiede zwischen Stadt und ländlichen Gebieten). Der Akzent der Medizin in Ghana liegt primär auf der kurativen und teils auf der rehabilitativen Medizin. Auf Vorsorge und Präventivmedizin liegt nur wenig Gewichtung (WHO 2013a, WHO 2013b).

Weltweit gab es 2008 etwa 8,795 Millionen Todesfällen bei Kindern unter 5 Jahren, davon waren 68\% (5,97 Millionen) durch Infektionen bedingt. Am häufigsten erlagen die Kinder Pneumonien (18\%), Diarrhoe (15\%) und Malaria (8\%). $41 \%$ der Todesfälle lagen im neonatalen Bereich, inklusive 12\% Todesfälle bei Frühgeborenen. 49\% der Kinder starben in nur 5 Ländern: Indien, Nigeria, Demokratische Republik Kongo, Pakistan und China (Black et al. 2010).

3,179 Millionen Kinder unter 5 Jahren sterben jährlich in der WHO-Region Afrika. Viele dieser Todesfälle könnten mit Hilfe von einfachen Präventions- und Therapiemaßnahmen verhindert werden. Es mangelt nach wie vor sowohl an Impf- und Aufklärungskampagnen als auch an wirksamen Antibiotika und adäquater Behandlung (WHO Child Survival 2012). Die WHO schreibt in dieser Zusammenfassung, mit erprobten Interventionen könnte die 
Kindersterblichkeit in Afrika um 66\% gesenkt werden, damit würden 2,8 Millionen Kinderleben jährlich gerettet (WHO Child Survival 2012).

23,5\% der Todesfälle in Ghana fallen in die Altersgruppe der 15- bis 60-Jährigen, während es in den Industrienationen nur etwa 7,4\% sind. Die Mortalität bei unter 5-Jährigen lag 2013 in Ghana bei 7,8\% (WHO 2013a). Die Haupterkrankungen und Todesursachen der unter 5Jährigen in Ghana waren 2013 Malaria (18\%), perinatale Komplikationen und Frühgeburtlichkeit (insgesamt 33\%), angeborene Anomalien (7\%), Lungenentzündungen (13\%), Durchfälle (7\%), Verletzungen (4\%), HIV/AIDS (3\%) und Masern (1\%) (WHO 2013a).

In Deutschland bei liegt die Mortalität der unter 5-Jährigern bei 0,4\%, wobei hier ein großer Anteil auf den Bereich der neonatologischen Intensivmedizin fällt: 34\% der Mortalität ist durch Frühgeburtlichkeit und perinatale Komplikationen bedingt, hinzu kommen 31\% Mortalität durch kongenitale Anomalien (WHO 2013b).

Einen Einflussfaktor für erhöhte Infektionsraten stellt die Schwächung des Immunsystems vor allem bei Kindern dar: Durch Mangelernährung, Masern- und HIV-Erkrankungen sowie chronischen Parasitenbefall (Helminthen, Malariaerreger) werden die Erkrankten zusätzlich anfällig für bakterielle Infektionen (Cotton et al. 2008, Echave et al. 2003, Ndip et al. 1995, Petit et al. 1995).

Die durchschnittliche Lebenserwartung liegt in Ghana bei 64 Jahren, in Deutschland bei 81 Jahren (WHO 2013a, WHO 2013b). 2012 waren noch 29\% der unter 5 jährigen Kinder in Afrika mangelernährt 10-29\% hatten 2008 keinen Zugang zu geprüften Trinkwasserquellen (WHO GLAAS 2008, WHO Malnutrition 2013).

In Ghana flossen 2007 8,3\% des Bruttoinlandproduktes und 10,7\% der gesamten Regierungsausgaben in den Gesundheitssektor, in Deutschland sind dies etwa 11,3\% (Statistisches Bundesamt 2013, WHO Statistical Fact Sheet 2010). In Zahlen bedeutet das für Ghana eine jährliche Pro-Kopf-Ausgabe von 75 Dollar, während der Betrag in Deutschland bei knapp 3.590 Dollar liegt (Statistisches Bundesamt 2013, WHO 2013a).

In Ghana wird die Wasserversorgung vielerorts durch Wassertanks gesichert, die bei Kontamination jedoch eine mögliche Quelle von Keimwachstum sind. In Ghana haben etwa 71-90\% der Bevölkerung Zugang zu sauberem Trinkwasser, allerdings haben nur 6-15\% der Bevölkerung Zugang zu verbesserten Sanitäranlagen (WHO GLAAS 2008, WHO 2013b). Es gibt Aufklärungskampagnen der WHO zum Thema Hygiene, da es nachweislich gehäuft zu Infektionen kommt, die durch mangelnde Händehygiene bedingt sind: von der Nahrungsmittelzubereitung bis hin zum Toilettengang. 
Viele Afrikaner südlich der Sahara leben in ländlichen Bezirken, in denen die Häuser nach alter Tradition noch immer aus Lehm, Stroh und Kuhmist gebaut werden. Die meisten Menschen dort leben zudem dicht an dicht mit landwirtschaftlichen Nutztieren zusammen, daraus resultiert ein weiteres Hygienedefizit, das die Entstehung von Infektionen begünstigt. Ein anderes Problem stellen die oft zeitlich sehr langen Anreisen dar, die Patienten in den Ländern des Südens - so auch in Ghana - auf sich nehmen müssen, um eine medizinische Behandlung zu bekommen. Dadurch verschlechtern sich der Verlauf, eine adäquate Therapie wird immer komplizierter (Commey et al. 1994, Echave et al. 2003).

Die medikamentöse Therapie von Infektionskrankheiten wird erschwert durch sich ausbreitende Resistenzen gegen die häufig eingesetzten Antibiotika. Fehldiagnosen, ein unangemessener Zugang zu Medikamenten, fehlende Aufklärung des medizinischen Personals sowie der Bevölkerung, finanzielle Defizite und mindere Qualität der eingesetzten Arzneimittel in den Ländern des Südens sind nur einige Faktoren, die zu dieser Resistenzentwicklung beitragen können (WHO Infectious Disease 2000). Hinzu kommt der Einsatz von Antibiotika in subtherapeutischen Dosen als Krankheitsprophylaxe, frühes Absetzen bei Besserung der Symptome aus finanziellen Gründen und die Anwendung von Antibiotika als Mastmittel von Nutztieren. Dadurch können Resistenzen bei den Bakterien entstehen, die sich unter bestimmten Voraussetzungen auch auf den Menschen übertragen (Manie et al. 1999, Mills-Robertson et al. 2002, Okolo 1986).

Der Mangel an objektiven Informationen über mögliche Nebenwirkungen und die oft inadequate Anwendung von Antibiotika sowie fehlende diagnostische Mittel schränken gezielte, effektive Therapien deutlich ein (Benbachir et al. 2001, Bosu und Ofori-Adjei 1997a, Bosu und Ofori-Adjei 1997b, Bosu und Ofori-Adjei 2000, Kesah et al. 2003, Petit et al. 1995).

Häufig greifen Patienten auch bei Antibiotika zur Selbstmedikation; da viele Medikamente in den Ländern des Südens nicht verschreibungspflichtig sind und somit frei erworben werden können (Bosu und Acquah 1996, Bosu und Ofori-Adjei 2000, Lamikanra et al. 1989, Manie et al. 1999).

Oft verordnen behandelnde Ärzte aus Mangel an diagnostischen Möglichkeiten mehrere Antibiotika gleichzeitig. In Ghana wurden 1997 pro Arztbesuch bis zu 4,3 Medikamente pro Patient verschrieben, einige davon waren seit Jahren nicht mehr auf dem westlichen Markt zugelassen. Fast die Hälfte der verschriebenen Arzneimittel waren Antiinfektiva (Bosu und Ofori-Adjei 1997a). Ein Grund für die massive Verschreibung von Antibiotika ist der Mangel 
an Aufklärung über die Ätiologie von beispielsweise Atemwegserkrankungen. Das führt bei den Patienten gegenüber dem Arzt zu der Erwartungshaltung, Antibiotika verschrieben zu bekommen. Die Ärzte wiederum wollen sich mangels diagnostischer Möglichkeiten absichern und verschreiben daher schneller als nötig Breitspektrumantibiotika und andere Medikamente (Bosu und Ofori-Adjei 1997a, Bosu und Ofori-Adjei 2000, Petit et al. 1995).

Trotz einer von der WHO herausgegebenen „Essential Drug List“ werden in afrikanischen Ländern immer noch für bestimmte Indikationen unwirksame oder obsolete Medikamente, die nicht auf der Liste stehen, verschrieben. Hinzu kommt, dass zu wenig Generika verschrieben werden, was zu hohen Gesundheitskosten beiträgt (Bosu und Ofori-Adjei 1997a, Bosu und Ofori-Adjei 2000, Petit et al. 1995). Dieses letztgenannte Problem besteht jedoch in Europa nicht minder.

\subsection{Bedeutung von MRSA}

Als besonderer Aspekt dieser Arbeit sollte die Prävalenz des Methicillin/Oxacillin-resistenten Staphylococcus aureus (MRSA) im Vergleich zwischen Ghana und Deutschland beschrieben und ihre möglichen Hintergründe und ihre Bedeutung in der Infektionsgenese erläutert werden. Der MRSA stellt - gemeinsam mit anderen multiresistenten Keimen - eine sich ausbreitende Gefahr im globalen Gesundheitswesen dar.

Koagulase-negative Staphylokokken (KNS) haben in den vergangenen Jahren ansteigende Resistenzraten, z.B. gegen Methicillin/Oxacillin aufgewiesen: in Norwegen, wo die MRSARate noch sehr gering ist, zeigten KNS Methicillin/Oxacillin-Resistenzraten bis 70-80\%. Sie werden von einigen Autoren als Reservoir für einige Resistenzgene bezeichnet. Vor dem Hintergrund, dass manche Resistenzen horizontal (über Gentransfer) an andere Bakterienstämme weitergegeben werden können, stellt diese Tatsache eine schwer einzuschätzende Gefahr dar (Hanssen et al. 2005, Hanssen et al. 2004).

Bei immunsupprimierten Patienten (wie z.B. HIV-infizierten Kindern in Südafrika) liegen die MRSA-Raten bei bis zu 77\% aller nachgewiesenen S. aureus-Isolate (Cotton et al. 2008). Im Hinblick auf die rasche Resistenzentwicklung bei MRSA sowie die Ausbreitung immunsupprimierender Krankheiten wie HIV, aber auch weiterhin bestehender sozioökonomischer Probleme wie Mangelernährung, bedeutet dies eine besondere Gefahr für den afrikanischen Kontinent. Die Nase gilt als Reservoir für MRSA, von wo aus er ggf. disseminierte Infektionen verursachen kann (Archer und Climo 2001, Lederer et al. 2007). 


\section{Einleitung}

\subsection{Fragestellungen:}

Diese Arbeit soll untersuchen, ob hinsichtlich der bakteriellen Nasenflora Unterschiede zwischen Ghana und Deutschland bestehen.

Dabei sollen folgende Fragen gestellt werden:

1. Gibt es Unterschiede in der Zusammensetzung der bakteriellen Nasenflora bei den Probanden aus Deutschland und jenen aus Ghana?

2. Wie ist die Rate der Antibiotikaresistenzen von Bakterien im Vergleich der Flora der Probanden beider Länder?

3. Lassen sich aufgrund des Anwendungsverhaltens im Umgang mit Antibiotika - z.B. Chloramphenicol - Rückschlüsse auf die Entwicklung bakterieller Resistenzen gegen Antibiotika ziehen?

4. Gibt es signifikante Unterschiede in der Prävalenz von MRSA (und anderen multiresistenten Keimen) zwischen Ghana und Deutschland?

5. Ist die Nase ein mögliches Reservoir für fakultativ pathogene Bakterien? 


\section{Experimenteller Teil - Patienten und Methoden}

\subsection{Probanden}

Es gab keine Ein- oder Ausschlusskriterien, um ein möglichst breites Spektrum an Probanden zu erhalten. Jedoch wurde so gut wie möglich versucht, relevante Faktoren (wie Alter, Erkrankungen, Einnahme von Antibiotika) der ghanaischen Kohorte mit der deutschen zu korrelieren. Jedem Freiwilligen wurde ein Nasenabstrich entnommen und mit ihm/ihr ein kurzer Fragenkatalog bearbeitet.

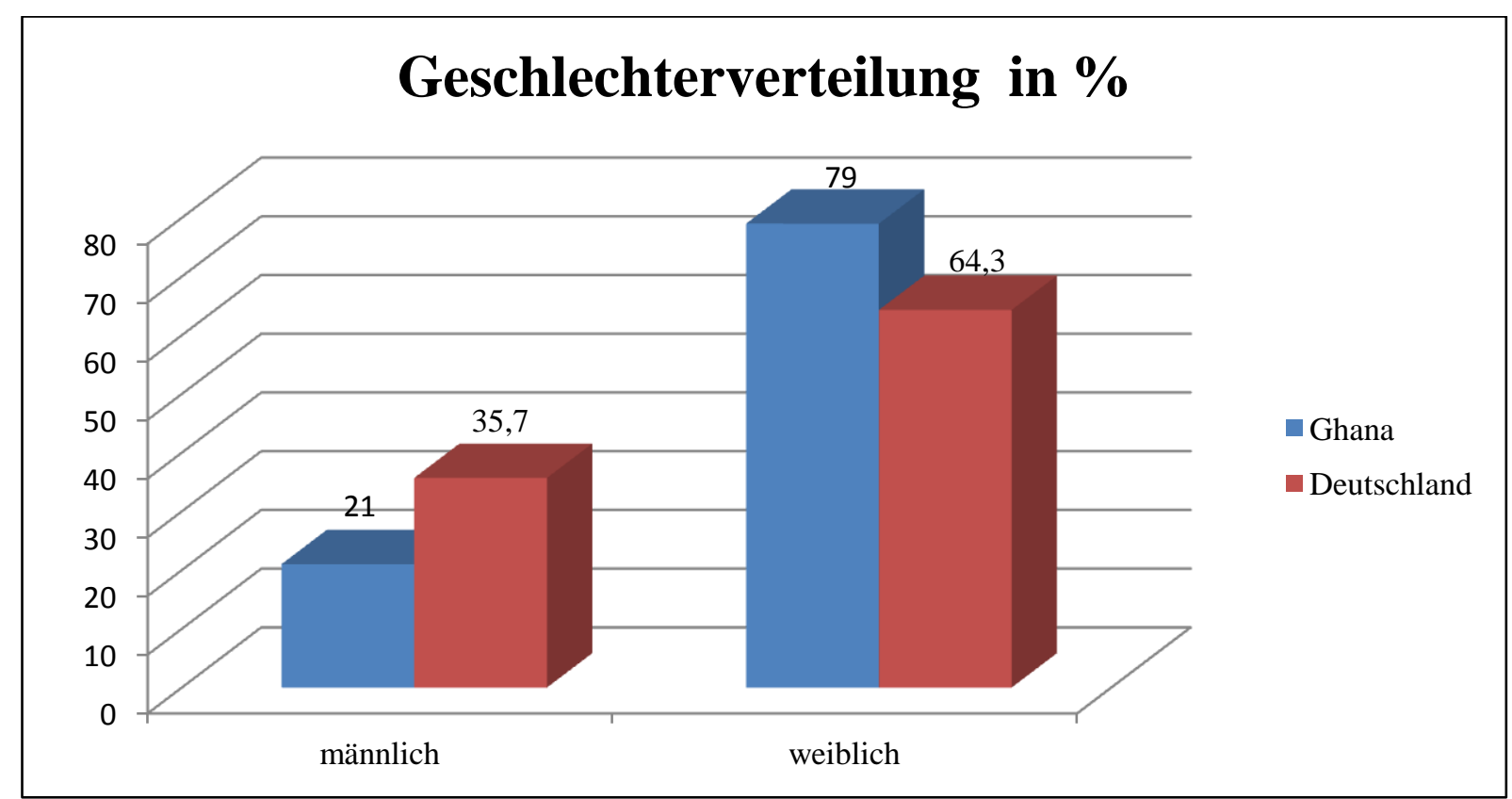

Abb.1: Geschlechterverteilung der Probanden in Ghana und Deutschland 


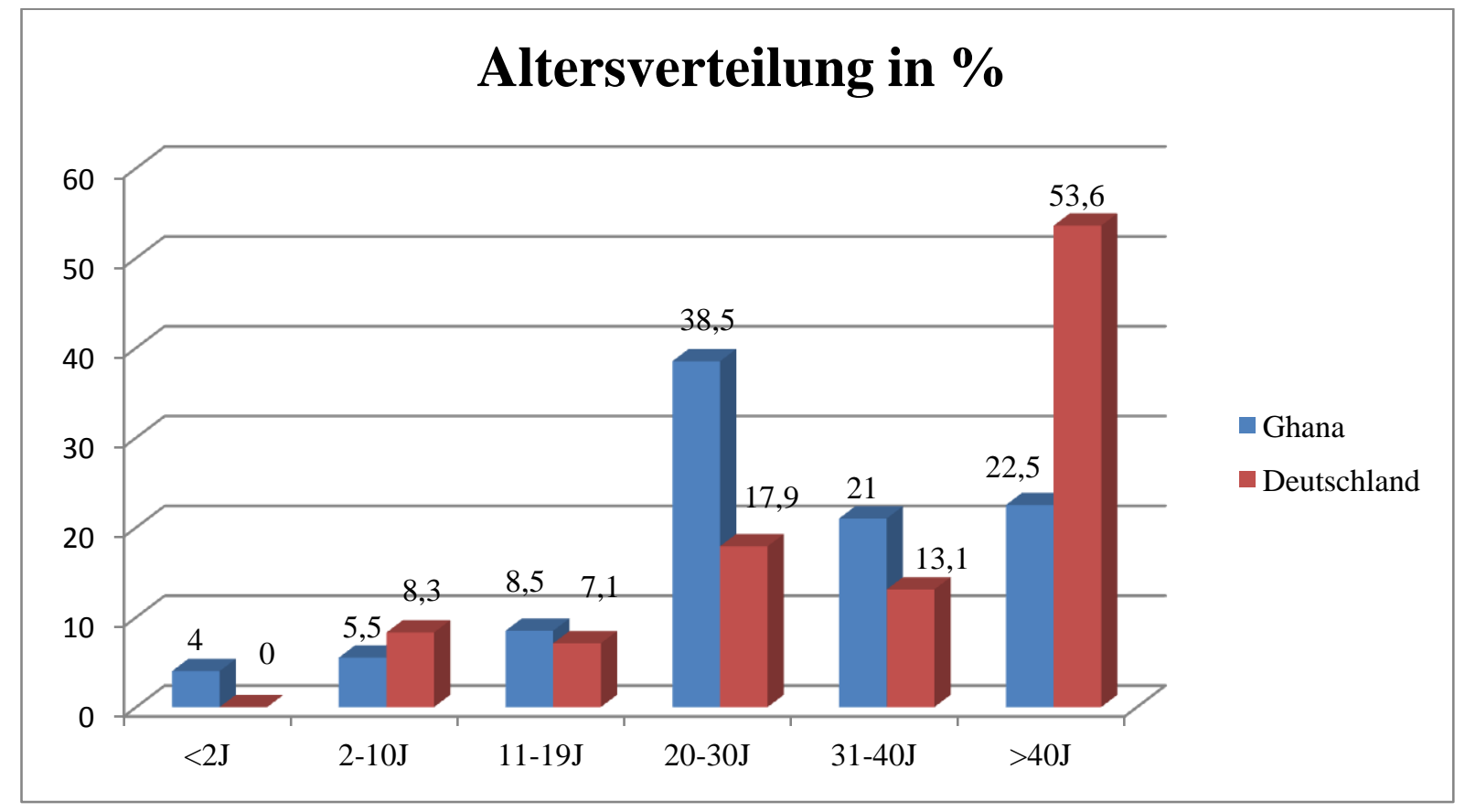

Abb.2: Altersverteilung der Probanden Ghana - Deutschland

\subsubsection{Patienten in Ghana}

Die Proben aus Ghana wurden von U. Groß und einigen Krankenhausmitarbeitern am 19.10.2001 in einem Zeitraum von ca. 2 Stunden im St. Martin de Porres-Krankenhaus in Eikwe im Südwesten von Ghana gewonnen. Um das Risiko, nosokomiale Keime in den Abstrichen zu finden, zu minimieren, erfolgte die Probenentnahme im ambulanten Bereich des Krankenhauses (Poliklinik).

Die Probanden wurden per Zufallsprinzip aus den ca. 500 ambulanten Patienten, die das Krankenhaus pro Tag aufsuchen, ausgewählt. Die Zustimmung der einzelnen Probanden wurde vorab eingeholt. Die Abstriche wurden in Ghana und Deutschland auf die gleiche Weise gewonnen, es handelt sich hierbei um Probengewinnung anhand von Rayon ${ }_{-}$ Abstrichtupfern „transsystem ${ }^{\circledR}$ “ mit Agar-Gel-Medium (Hain Lifescience GmbH, Nehren, Deutschland). Dabei wird ein steriler Wattetupfer in die Nase des Probanden eingeführt, mehrmals hin und her bewegt und dann in das Abstrichröhrchen mit fertigem Nährboden gegeben.

Es erfolgte dann der Transport der Proben nach Deutschland, wo sie ausgewertet wurden. 
Jedem Probanden wurden im Rahmen einer Anamnese einige Fragen gestellt, die sich auf Vorerkrankungen, Erkrankungen zum Zeitpunkt der Probenentnahme sowie die Einnahme von Antibiotika bezogen. Außerdem wurden Alter und Geschlecht festgehalten, um die deutsche Gruppe entsprechend vergleichen zu können. Unter den ghanaischen Probanden waren 158 weibliche sowie 42 männliche Probanden. (Siehe Abb.1) Die Altersverteilung beider Gruppen wird in Abb.2 dargestellt.

\subsubsection{Probanden in Deutschland}

Die Probenentnahme in der deutschen Kontrollgruppe erfolgte durch mich und drei Helfer. Es wurde dazu aus logistischen Gründen eine größere Veranstaltung des Missionsärztlichen Institutes in Würzburg, die am 06.07.2002 stattfand, genutzt. Der Ort wurde gewählt, um in kurzer Zeit eine möglichst hohe Anzahl von Proben zu gewinnen, da eine dem ambulanten Krankenhaus in Ghana entsprechende Einrichtung mit derart hohen Patientenzahlen nicht zur Verfügung stand. Daher wäre die Probenentnahme in einer deutschen Klinikambulanz wesentlich zeitaufwendiger und störanfälliger (z.B. chronisch Kranke mit pathologischer Besiedlung) gewesen. Die Besucher dieser Veranstaltung wurden über den Vorgang der Probenentnahme informiert und konnten sich dann freiwillig dazu melden. Insgesamt wurden 101 Nasenabstriche entnommen, da jedoch 17 dieser Proben ohne Keimwachstum blieben, gingen nur die Abstriche von 84 Probanden in die Statistik ein.

\subsubsection{Fragebogen}

In einem Fragenkatalog wurde bei allen Probanden eine Kurzanamnese über vorangegangene Krankheiten und den Gebrauch von Antibiotika im Vorfeld erhoben. In beiden Ländern wurde bei Abnahme des Nasenabstriches zunächst das Datum, Geschlecht und Alter des Probanden erfragt sowie die Krankheiten innerhalb des letzten Jahres, die aktuelle Einnahme von Antibiotika und die Einnahme von Antibiotika innerhalb der vorangegangenen 4 Wochen (möglichst mit Bezeichnung des Präparates) erfragt. Der Fragebogen für Ghana beinhaltete darüber hinaus die Hauptdiagnose bzw. den Grund der ambulanten Vorstellung. Bei der deutschen Kontrollgruppe wurde zusätzlich der letzte Tropenaufenthalt abgefragt, um die Wahrscheinlichkeit einer klimatischen Beeinflussung abwägen zu können. Den Probanden wurden Nummern zugeteilt. Der Fragebogen sollte dazu dienen, die Kohorten annähernd zu 
korrelieren sowie Erkrankungen und Therapien zu erfassen, die einen potenziellen Einfluss auf die Ergebnisse hätten haben können.

Übersichtstabelle über den Fragebogen und die länderspezifischen Fragen:

\begin{tabular}{|l|l|l|l|l|l|l|l|}
\hline Ghana: & Nr. & Geschlecht & Alter & $\begin{array}{l}\text { Haupt- } \\
\text { diagnose }\end{array}$ & $\begin{array}{l}\text { Erkrankungen } \\
\text { im letzten } \\
\text { Jahr }\end{array}$ & $\begin{array}{l}\text { Antibiotika } \\
\text { heute }\end{array}$ & $\begin{array}{l}\text { Antibiotika- } \\
\text { einnahme } \\
\text { innerhalb } \\
\text { der letzten } \\
\text { 4 Wochen }\end{array}$ \\
\hline $\begin{array}{l}\text { Deutsch- } \\
\text { land: }\end{array}$ & Nr. & Geschlecht & Alter & $\begin{array}{l}\text { Letzter } \\
\text { Tropen- } \\
\text { aufenthalt }\end{array}$ & $\begin{array}{l}\text { Erkrankungen } \\
\text { im letzten } \\
\text { Jahr }\end{array}$ & $\begin{array}{l}\text { Antibiotika } \\
\text { heute (zur } \\
\text { Zeit) }\end{array}$ & $\begin{array}{l}\text { Antibiotika- } \\
\text { einnahme } \\
\text { innerhalb } \\
\text { der letzten } \\
\text { 4 Wochen }\end{array}$ \\
\hline
\end{tabular}

\subsection{Methoden}

\subsubsection{Bakterienanzucht}

Die Anzucht und Isolation der Bakterienstämme sowie die Erstellung der Antibiogramme erfolgte im Institut für Medizinische Mikrobiologie der Universitätsmedizin Göttingen. Bis zum Zeitpunkt der Anzucht lagerten die Abstrichtupfer im Kühlschrank.

Um die einzelnen Bakterienstämme differenzieren und isolieren zu können, musste das Material, also die gewonnenen Nasenabstriche, zuerst auf Nährböden (Agar) geimpft werden. Dies geschah in Form eines fraktionierten Dreiösenausstriches. Jeder Watteträger wurde zum Zweck der besseren Differenzierung auf drei verschiedene Agarplatten geimpft: Blutagar, Endoagar und Clauberg-Agar. Nachdem die Isolation der Bakterien abgeschlossen war, wurden die einzelnen Stämme auf Müller-Hinton-Agar bzw. Blutagar zur Erstellung von Antibiogrammen ausgestrichen. Die Zutaten der verschiedenen Agar-Medien setzen sich folgendermaßen zusammen:

Blutagar ist ein unselektiver Nährboden, der sich auch zur Anzucht empfindlicher und anspruchsvoller Bakterien eignet. Eine weitere günstige Eigenschaft des Blutagars ist die Möglichkeit des Nachweises von Bakterien mit hämolysierenden Eigenschaften. Ein Liter Nährmedium enthält $10 \mathrm{~g}$ Herzextrakt, $10 \mathrm{~g}$ Fleischpepton, $5 \mathrm{~g}$ Natriumchlorid und $11 \mathrm{~g}$ Agar. 
Diese Zusätze werden in einem Liter destilliertem Wasser erhitzt und gelöst. Nach dem Abkühlen wird 5-10\% defibriniertes Schaf- oder Pferdeblut zugesetzt. Das Medium hat einen pH-Wert von 7,0 +/- 0,2.

Endo-Agar besteht aus einer Zubereitung von $10 \mathrm{~g}$ Pepton, 3,5 g Kaliumphosphat, $10 \mathrm{~g}$ Lactose, 2,5 g Natriumsulfit und $10 \mathrm{~g}$ Agar. $36 \mathrm{~g}$ dieser Zusammensetzung werden in einem Liter destilliertem Wasser suspendiert und unter Zugabe von einer 10\% alkoholischen Lösung von Basisfuchsin (in 95\% Ethanol) gelöst. Der pH-Wert liegt bei 7,5 +/- 0,2. Endo-Agar eignet sich zur selektiven Anzucht von Enterobacteriaceae und Non-Fermentern.

Der Clauberg-Agar selektiert vor allem Enterococcus faecalis und coryneforme Bakterien, es können jedoch in gehemmter Form auch Staphylokokken, Proteus und Listerien darauf wachsen. Ein Liter Clauberg-Agar enthält $8 \mathrm{~g}$ Fleischpepton, $8 \mathrm{~g}$ Fleischextrakt, $4 \mathrm{~g}$ Natriumchlorid, $320 \mathrm{mg}$ Kaliumtellurit, $20 \mathrm{ml}$ Blutglycerolat, $15 \mathrm{~g}$ Agar und $140 \mathrm{ml}$ Schafblut. Der pH-Wert liegt bei 7,7 +/-0,2.

Die Zusammensetzung des Müller-Hinton-Agars besteht aus 30\% Rindfleischaufguss, $1,75 \%$ hydrolysiertem Casein, 0,15\% Stärke, 1,7\% Agar. Das Medium ist bei $25{ }^{\circ} \mathrm{C} \mathrm{pH}$ neutral.

Nach Beimpfung wurden die Agarplatten für 24 Stunden bei 37 Grad bebrütet, bei geringem oder fehlendem Anwuchs erfolgte ein weiterer Tag Bebrütung.

Die verschiedenen, meist schon makroskopisch differenzierbaren Bakterien wurden dann auf einzelne Blutplatten isoliert und wiederum 24 Stunden bebrütet, um sie sauber voneinander trennen zu können.

\subsubsection{Differenzierung}

Um die einzelnen Bakterienstämme voneinander abgrenzen $\mathrm{zu}$ können, wurden Gramfärbungen angefertigt und bestimmte Enzymreaktionen getestet. Diese Verfahren wurden nach den üblichen Laborstandards durchgeführt:

Die Gramfärbung macht sich den unterschiedlichen Aufbau der Zellwand der einzelnen Bakterien zunutze. Um eine Gramfärbung anfertigen zu können muss zunächst ein bakterienhaltiger Objektträger luftgetrocknet und über einem Bunsenbrenner hitzefixiert werden. Dann wird der Farbstoff Gentianaviolett auf den Objektträger gegeben und wirkt 3 
Minuten ein. Anschließend wird das Präparat mit Lugollösung (Jod-Jodkalium) beträufelt, die 2 Minuten einwirken muss. Es wird dann mit Wasser und alkoholischen Lösungsmitteln (Ethylalkohol bzw. einer Alkohol-Azeton-Mischung) so lange gespült, bis keine sichtbaren Farbwolken mehr abgehen. Zuletzt muss die Probe noch für eine Minute mit Fuchsinrot gegengefärbt und dann mit Wasser abgespült werden. Daraufhin wird das Präparat getrocknet und kann unter einem Mikroskop betrachtet werden. Die grampositiven Bakterien erscheinen blauschwarz bis dunkelviolett, während die gramnegativen Stämme rosafarben bis fuchsinrot imponieren.

Zur weiteren Differenzierung dienten enzymatische bzw. biochemische Verfahren:

Zur Differenzierung zwischen Staphylokokken und Streptokokken wird der Katalasetest verwendet. Hierzu fügt man auf bereits auf den Objekträger gegebenes Bakterienmaterial wenige Tropfen 3\%-ige Wasserstoffperoxidlösung. Staphylokokken enthalten das Enzym Katalase, das unmittelbar nach dem Auftropfen zur Gasbildung führt, da es das $\mathrm{H}_{2} \mathrm{O}_{2} \mathrm{zu}$ Wasser und Sauerstoff spaltet. $\left(2 \mathrm{H}_{2} \mathrm{O}_{2} \rightarrow 2 \mathrm{H}_{2} \mathrm{O}_{+} \mathrm{O}_{2}\right)$. Diese Reaktion ist bei Streptokokken nicht zu beobachten.

Der Koagulasetest unterscheidet Koagulase-positive Staphylococcus aureus von Koagulasenegativen Staphylokokken: Auf einen Objektträger wird hierfür ein Tropfen Zitratplasma gegeben, in den eine Kolonie des zu untersuchenden Bakteriums hinein gerieben wird. Flockt die Flüssigkeiten nach Bewegen des Objektträgers aus, so handelt es sich um S. aureus, der das Enzym Plasmakoagulase bildet. Ist der Test negativ, und es wurden mikroskopisch grampositive Haufenkokken gesehen, die Katalase-negativ getestet wurden, so handelt es sich um Koagulase-negative Staphylokokken.

Der Oxidasetest weist das Atmungskettenenzym Cytochromoxidase nach. Es wird etwas Bakterienmaterial auf ein Testplättchen gegeben oder eine Oxidasetestlösung auf die Agarplatte getropft. Kommt es zu einer Blaufärbung (Reduktion des Cytochromoxidasesystems anhand von künstlichen Oxidantien), ist die Reaktion „Oxidase-positiv“. Gramnegative Kokken wie Neisserien, aber auch definierte gramnegative Stäbchen, (z.B. Pseudomonas) besitzen Cytochromoxidase und können so nachgewiesen werden. 
Um die Enterobakterien differenzieren zu können, wurde die sogenannte „,bunte Reihe“ oder API (Analytical Profile Index) angewendet. Dies ist ein Testsystem, mit dem verschiedene enzymatische Reaktionen durchgeführt werden können, aus deren Resultatkombination auf die Bakterienart geschlossen werden kann. In dieser Arbeit wurde dazu der BBL ${ }^{\mathrm{TM}}$ Enterotube $^{\mathrm{TM}}$ II von der Firma Becton Dickinson (Heidelberg, Deutschland) verwendet.

\subsubsection{Erstellen der Antibiogramme}

Um die Sensibilität der unterschiedlichen Bakterienstämme auf eine Gruppe von Standardantibiotika zu testen, werden Agardiffusionstests erstellt. Dazu wird jeder isolierte Bakterienstamm in Kochsalz aufgelöst und mit einem Watteträger auf eine Blut- bzw. MüllerHinton-Agarplatte kreuzweise dicht geimpft. Diese wird anschließend mit einem Stempel beschickt. Dieser Stempel enthält in definierten Abständen Filterpapierplättchen, die mit unterschiedlichen Antibiotika getränkt sind. Von den Plättchen aus diffundieren die Substanzen in den Nährboden und erzeugen bei Empfindlichkeit der Bakterien sogenannte Hemmhöfe, in denen kein Bakterienwachstum mehr stattfinden kann. Ist das Bakterium resistent gegen das getestete Antibiotikum, so ist kein Hemmhof vorhanden, oder er ist kleiner als ein definierter Grenzwert. In dieser Arbeit wurden sämtliche Keime auf Empfindlichkeit gegenüber den 12 folgenden Antibiotika getestet: Ampicillin/Amoxicillin, Cefazolin (als Beispiel eines Basiscephalosporins der zweiten Generation), Vancomycin, Chloramphenicol, Gentamicin, Ciprofloxacin, Tetracyclin, Co-Trimoxazol, Penicillin G, Oxacillin, Erythromycin, Lincosamin/Clindamycin.

\subsection{Statistik}

Alle Ergebnisse sind als Säulendiagramme, erstellt mit Hilfe von Excel-Tabellen, dargestellt. Die Signifikanzen wurden als p-Wert anhand des Programmes Statistika Version 10 mit dem $\mathrm{Chi}^{2}$-Test für nichtparametrische Verfahren errechnet. Bei Stichproben mit Zahlen von $\mathrm{n}<5$ wurde der Fishers-exakt-Test verwendet, obwohl diese Stichproben kaum als repräsentativ angesehen werden können und eher am Rande erwähnt werden. Es werden vor allem Ergebnisse mit größeren Stichprobenzahlen diskutiert, bei denen der p-Wert <0,05 ist, die also statistisch signifikante Aussagen beihalten. 


\section{Ergebnisse}

\subsection{Die Zusammensetzung der nasalen Bakterienflora}

Die Untersuchungen der Nasenflora von Probanden aus Ghana im Vergleich mit deutschen Probanden ergaben in einigen Bereichen Übereinstimmungen, in anderen Bereichen wiederum starke Unterschiede.

Die exakten Zahlen der mikrobiellen Identifizierungen, bzw. ihre prozentualen Anteile lassen sich aus den graphischen Darstellungen entnehmen. Da es in dieser Arbeit um eine grob orientierende Darstellung der Bakterienverteilung geht, wurde auf detailliertes Bestimmen von Subspezies verzichtet. Im Bereich der gramnegativen Bakterien werden nur die häufig nachgewiesenen und mit oben genannten Testverfahren $\mathrm{zu}$ differenzierenden Bakterien konkret benannt, alle anderen gramnegativen Stäbchen werden, gemeinsam mit Acinetobacter spp., als Non-Fermenter subsummiert. An manchen Stellen sind die Bakterien definierten mikrobiologischen Gruppen zugeordnet, um die Zahl der Stichproben ausreichend hoch zu halten.

Außerdem wurden in 36,5\% der Proben aus Ghana Hefen nachgewiesen und bei 19,0\% der Abstriche wurden Schimmelpilze isoliert (siehe Abb.4). In den Nasenabstrichen deutscher Probanden konnten keine Hefen nachgewiesen werden und nur in 2,0\% waren Schimmelpilze nachweisbar. Diese wurden jedoch nicht weiter spezifiziert, da sie wahrscheinlich als sekundäre Verunreinigung einzustufen sind und nicht in die Fragestellung der Arbeit fallen.

Zunächst wurden folgende Gruppen von Bakterien definiert: apathogene Bakterien, auch kommensale oder permanente Flora genannt, und fakultativ pathogene Bakterien, die hier auch als transiente Flora bezeichnet wurden. In nur 17,5\% der Abstriche $(n=35)$ aus Ghana war ausschließlich eine als apathogen klassifizierte Nasenflora nachzuweisen, während in $57,1 \%$ der deutschen Abstriche $(\mathrm{n}=48)$ exklusiv apathogene Kommensalen der Nasenschleimhaut nachgewiesen wurden ( -Wert $<0,0001$ ). Davon stellten in beiden Kollektiven den größten Anteil mit etwa jeweils der Hälfte der Abstriche Koagulase-negative Staphylokokken (z.B. Staphylococcus epidermidis) dar: Bei 49,0\% der ghanaischen Probanden und bei 59,5\% der deutschen Probanden fanden sich Koagulase-negative Staphylokokken im Nasenabstrich. Somit gab es in diesem Punkt keinen signifikanten Unterschied ( $\mathrm{p}$-Wert=0,11). Coryneforme Bakterien traten in den Abstriche ghanaischer 
Ergebnisse

Probanden signifikant häufiger auf (p-Wert 0,0001), sie waren hier in 55,0\% der Abstriche zu finden ( $\mathrm{n}=110)$, während nur in 29,8\% der Proben deutscher Probanden coryneforme Bakterien nachgewiesen wurden $(\mathrm{n}=25)$. Neisserien wurden in $11,5 \%$ der Nasenabstriche des ghanaischen Kollektives $(n=23)$ und 1,2\% $(n=1)$ der Abstriche des deutschen Kollektives nachgewiesen (p-Wert 0,0018). Bacillus ssp. fanden sich bei den Patienten aus Ghana in 20,5\% der Abstriche $(n=41)$, in den Abstrichen der deutschen Kontrollgruppe war Bacillus zu $1,2 \%(\mathrm{n}=1)$ nachweisbar ( $\mathrm{p}$-Wert <0,0001). Bacillus ssp. werden jedoch ebenso wie Hefen und Pilze eher als Verunreinigung eingestuft.

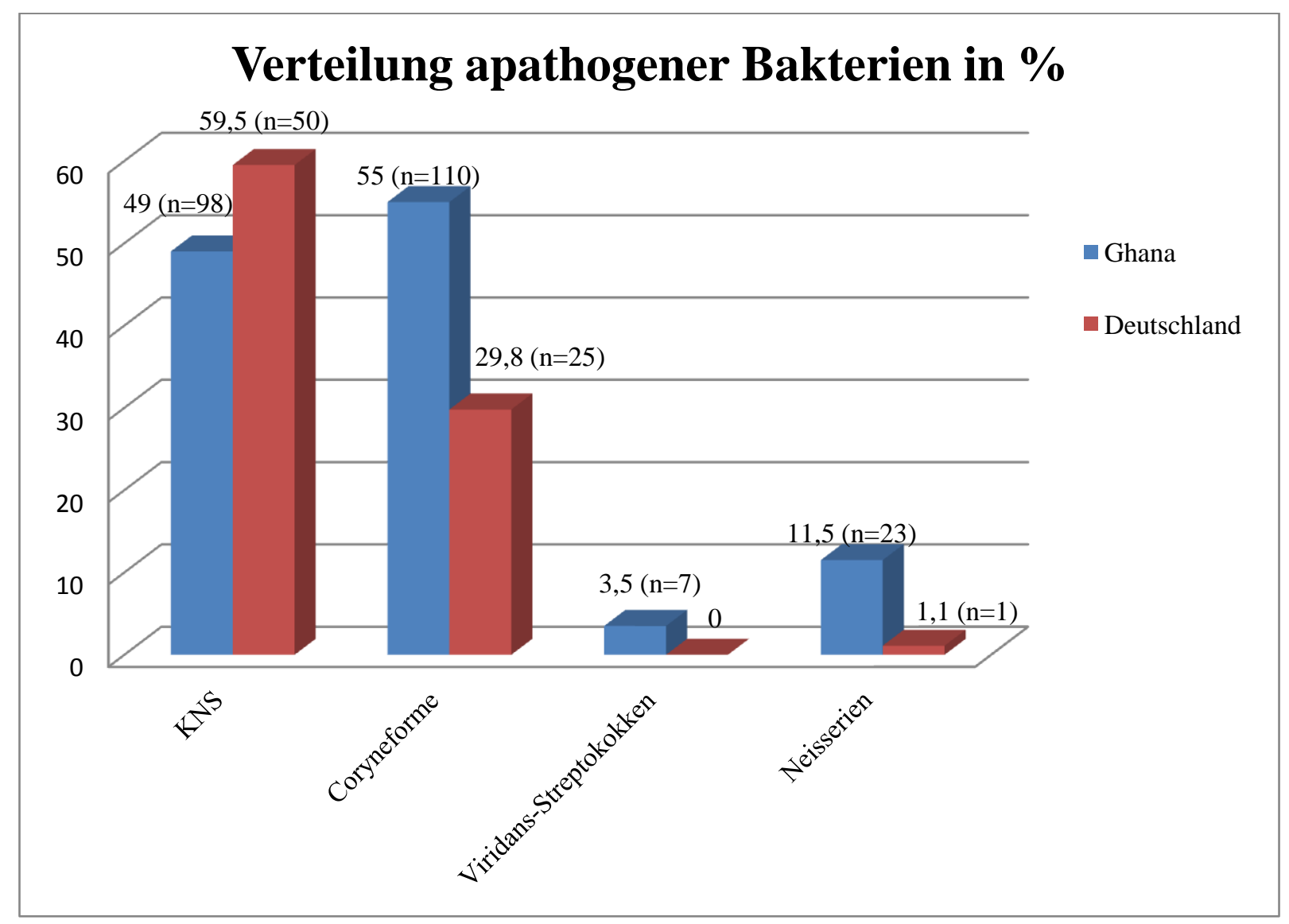

Abb.3: Verteilung der apathogenen Flora in Nasenabstrichen von ghanaischen und deutschen Probanden 


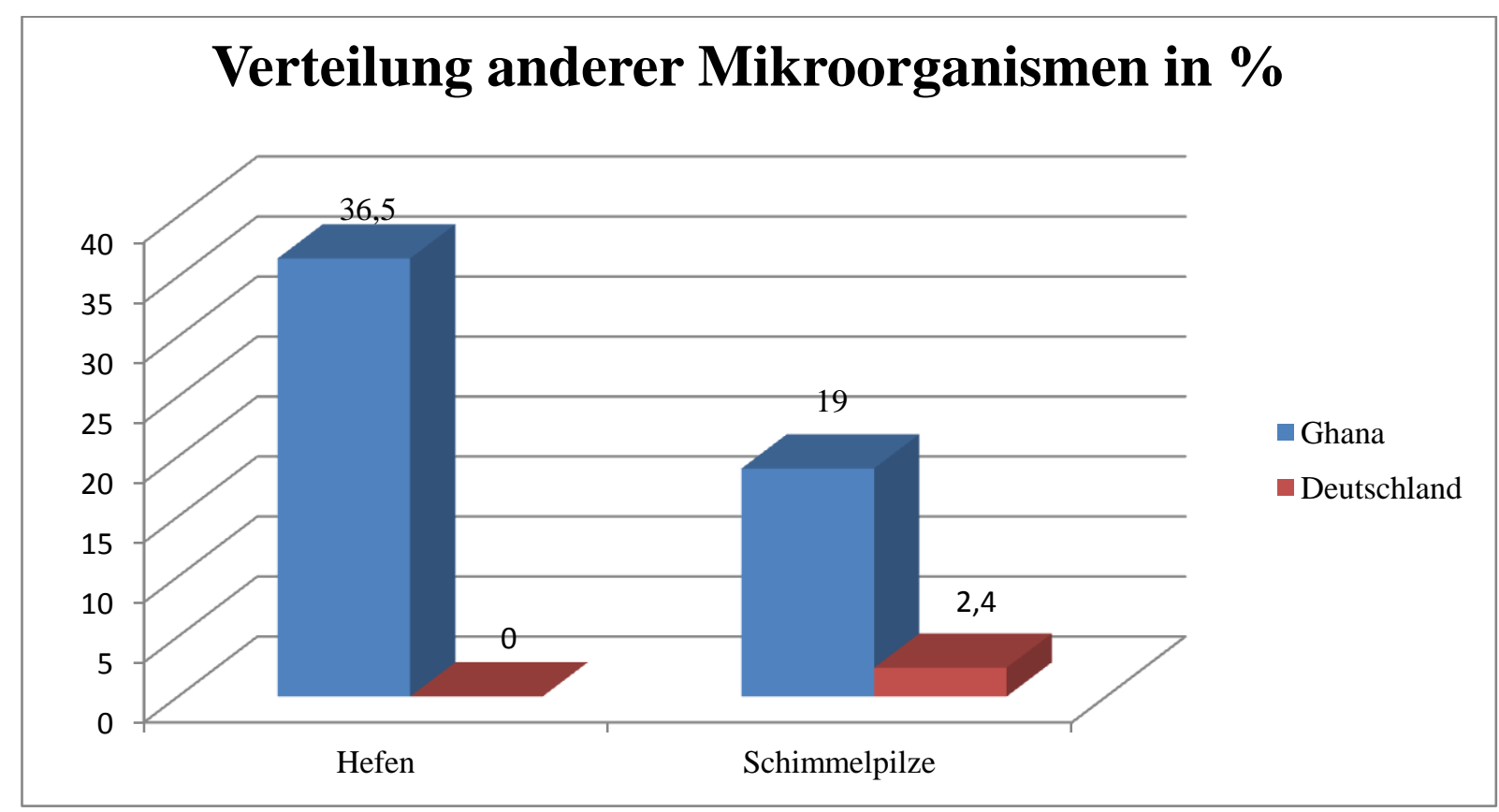

Abb.4: Weitere Mikroorganismen, für diese Studie nicht relevant, im Vergleich der Nasenabstriche ghanaischer und deutscher Probanden

Ein signifikanter Unterschied ist jedoch, dass bei den Proben ghanaischer Patienten ausnahmslos in jedem einzelnen Abstrich Bakterien nachgewiesen werden konnten, während im deutschen Kollektiv 16,8\% ( $\mathrm{n}=17)$ der Abstriche steril blieben ( $\mathrm{p}$-Wert <0,001). Wie im Diskussionsteil näher erläutert, wird dies am ehesten auf Abnahmefehler zurückgeführt. Die Referenzzahl der deutschen Abstriche wurde daraufhin von $n=101$ auf $n=84$ herunter gesetzt, um die Ergebnisse auf alle auswertbaren Abstriche zu korrelieren.

Eine Mischflora von fakultativ pathogenen Keimen und apathogenen Kommensalen war bei 63,5\% der ghanaischen und 14,3\% der deutschen Probanden nachweisbar (p-Wert <0,001). Sowohl dieses Ergebnis, als auch der Unterschied in der Gesamtzahl der fakultativ pathogenen Keime (82,5\% in Ghana, 36,6\% in Deutschland; p-Wert 0,002) sind statistisch signifikant.

Die Zusammensetzung der fakultativ pathogenen Flora bestand bis auf einzelne Ausnahmen vor allem aus Staphylococcus aureus, Enterobacteriaceae, Pseudomonas/Stenotrophomonas sowie Nocardien. Hier sind nun die größten signifikanten Unterschiede zu verzeichnen. Staphylococcus aureus kam in beiden Gruppen etwa gleich häufig vor: 17,0\% in den Abstrichen ghanaischer Probanden $(n=34), 19,0 \%$ in denen deutscher Probanden $(n=16+1$, in einem Abstrich fanden sich 2 verschiedene Stämme, daher wird an anderer Stelle eine Anzahl von $17 \mathrm{~S}$. aureus-Isolaten beschrieben). Ein entscheidender Unterschied zeigte sich darin, dass in 6 der Abstriche der ghanaischen Patienten die isolierten S. aureus (17,7\% der Stämme) 
Methicillin/Oxacillin-resistent waren. In den Abstrichen der deutschen Kontrollgruppe wurden keine MRSA isoliert. Diese Daten sind jedoch wegen der geringen Stichprobenzahl als nicht statistisch signifikant zu werten ( $\mathrm{p}$-Wert $<0,075$ ).

Bei den Enterobacteriaceae, zeigte sich eine signifikant unterschiedliche Häufigkeit: Während in den Nasenabstrichen aus Ghana 74 Isolate (37,0\%) nachgewiesen wurden (beinhaltet Enterobacter spp., E. coli spp., Citrobacter spp., Klebsiella spp., Proteus spp., Pantoea spp.), konnten in der deutschen Kontrollgruppe nur aus 5 Abstrichen Enterobacteriaceae $(6,0 \%)$ isoliert werden ( $\mathrm{p}$-Wert <0,0001). Teilweise waren in einzelnen Proben verschiedene Enterobacteriaceae nachweisbar. Proteus fand sich in 7,0\% der Abstriche ghanaischer Patienten $(n=14)$ sowie in 2,4\% der Abstriche der deutschen Probanden $(n=2)$. Enterobacter spp. enthielten $15,0 \%$ der Proben aus Ghana $(n=30)$ sowie 1,2\% derer aus Deutschland $(n=1)$. Bei E. coli und Pantoea spp. lag die Verteilung in beiden Kohorten bei 1,0-2,0\%. In den Abstrichen der deutschen Kontrollgruppe fanden sich keine Hinweise auf das Vorkommen von Citrobacter spp., während diese Bakteriengattung in den Abstrichen aus Ghana zu 6,5\% $(n=13)$ zu finden war (p-Wert 0,009).

Signifikante Differenzen ergaben sich bei Pseudomonas/Stenotrophomonas, die in 23 der Abstriche aus Ghana (11,5\%) und nur in einem Abstrich eines deutschen Probanden $(1,2 \%)$ nachweisbar waren (p-Wert $<0,0034)$. Unter den sonstigen Non-Fermentern ergab sich eine Verteilung von 57 Isolaten in den Nasenabstrichen aus Ghana (28,5\%) und 16 Isolaten in den Proben aus Deutschland (19\%) und somit kein signifikanter Unterschied (p-Wert >0,43).

Enterococcus faecalis war in 5,0\% der Proben aus Ghana $(n=10)$ enthalten sowie in 1,2\% der deutschen $(n=1), 4,5 \%$ der ghanaischen Proben enthielten Nocardien $(n=9)$, welche in 1,2\% der deutschen Abstriche $(n=1)$ zu finden waren. Hier ergaben sich bei geringer Stichprobenanzahl kein signifikanter Unterschied (p-Wert <0,095; p-Wert 0,123).

Andere, weniger relevante Keime waren vereinzelt nachweisbar, jedoch in so geringer Zahl, dass sie hier nicht erwähnt werden. Eine Übersicht über die fakultativ pathogenen Bakterien soll Abb. 5 ergeben. 


\section{Verteilung fakultativ pathogener Bakterien in \%}
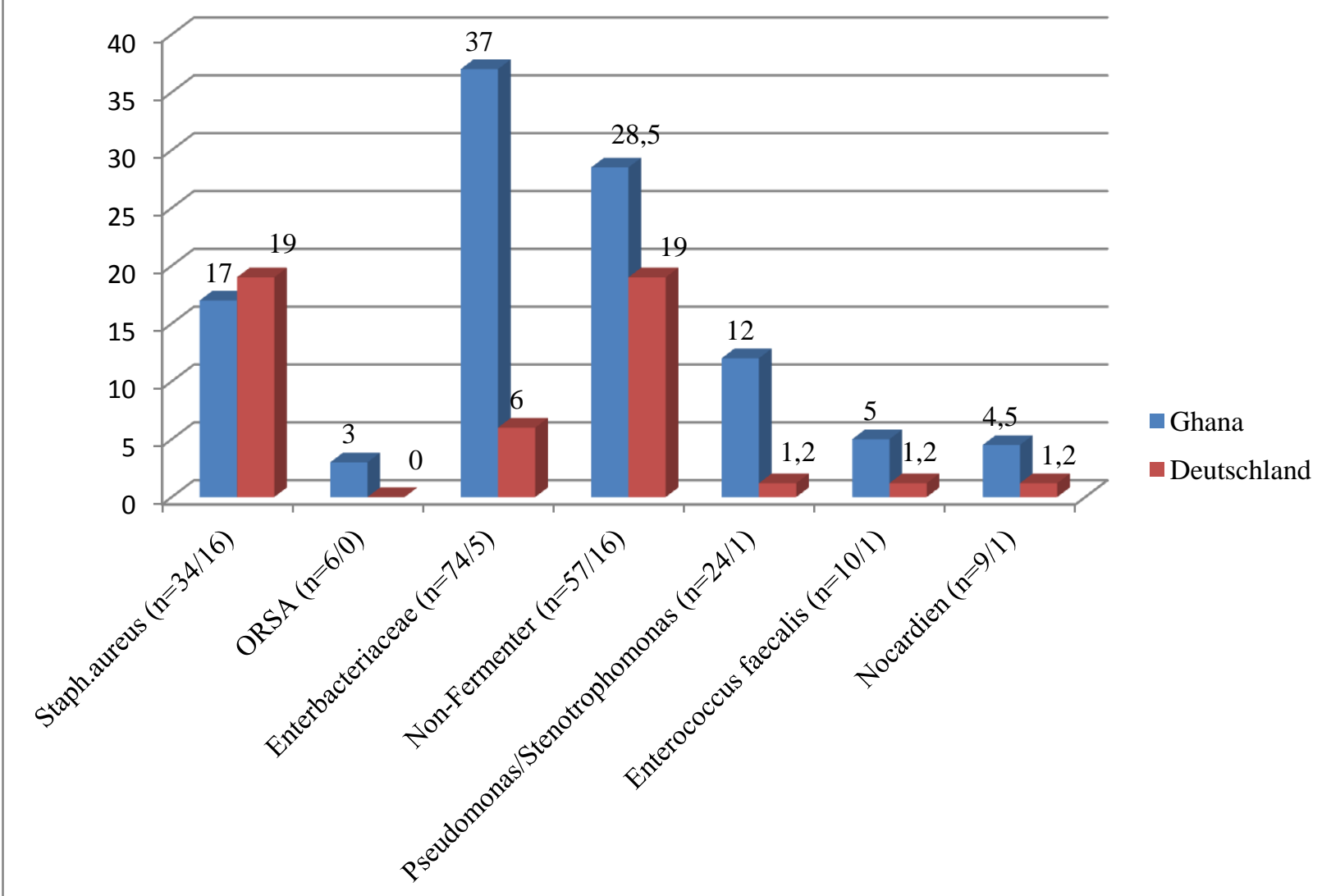

Abb 5: Verteilung der fakultativ pathogenen Bakterien aus Nasenabstrichen ghanaischer und deutscher Probanden

\subsection{Die Resistenzlage}

Die nachgewiesenen Bakterien wurden ebenfalls auf ihr Spektrum von Antibiotikaresistenzen getestet. Das Ergebnis der Proben aus Ghana zeigte, dass 47,0\% der Koagulase-negativen Staphylokokken jeweils Penicillin G- und Ampicillin-Resistenzen aufwiesen, 74,0\% resistent gegen Lincosamin und 40,0\% resistent gegen Methicillin/Oxacillin und Cephalosporin waren. 5,0\% waren resistent gegen Erythromycin, 4,0\% gegen Gentamicin, 5,0\% gegen Ciprofloxacin, 48,0\% gegen Chloramphenicol, 22,0\% gegen Tetracyclin und 6,0\% gegen Cotrimoxazol. Vancomycin war wirksam bei allen getesteten KNS.

Bei den KNS, die in den Abstrichen der deutschen Probanden gefunden wurden lag die Penicillin G-Resistenz und die Ampicillin-Resistenz bei 34,0\%, die Methicillin/Oxacillin-, Ciprofloxacin- und Cephalosporin-Resistenz bei 10,0\%, 42,0\% waren Erythromycin-resistent und die Resistenzrate gegen Gentamicin und Chloramphenicol lag bei 2,0\%. 24,0\% waren resistent gegen Tetracycline und 8,0\% zeigten Cotrimoxazol- und Lincosamin-Resistenzen, 
Ergebnisse

aber auch hier waren alle getesteten Bakterien sensibel gegenüber Vancomycin. Signifikant sind diese Unterschiede für Methicillin/Oxacillin (p-Wert<0,005), Erythromycin, Lincosamid und Chloramphenicol (p-Wert< 0,0001).

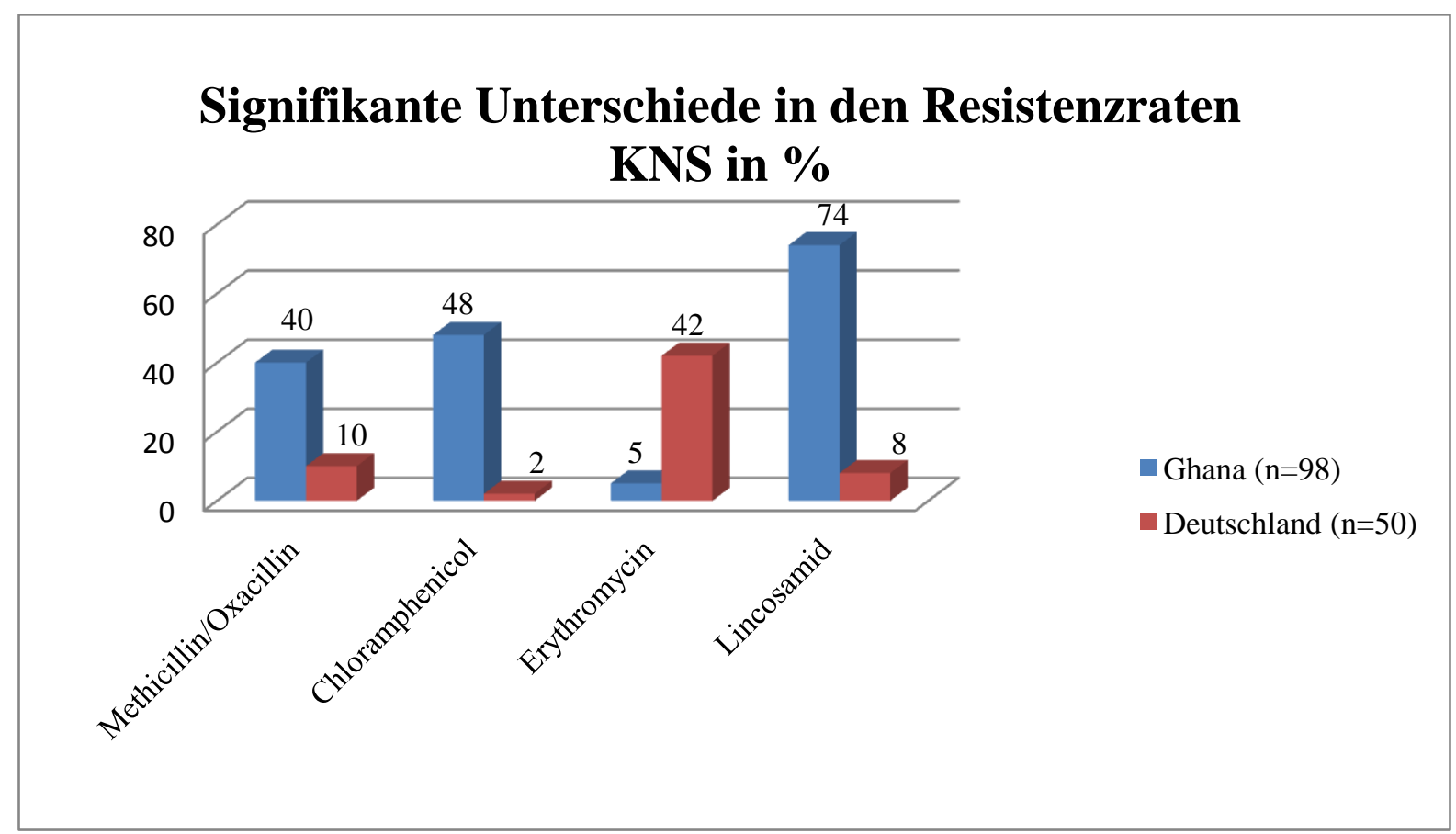

Abb.6: Signifikante Unterschiede in den Resistenzraten der Koagulase-negativen Staphylokokken im Vergleich der Abstriche von Probanden aus Ghana und Deutschland

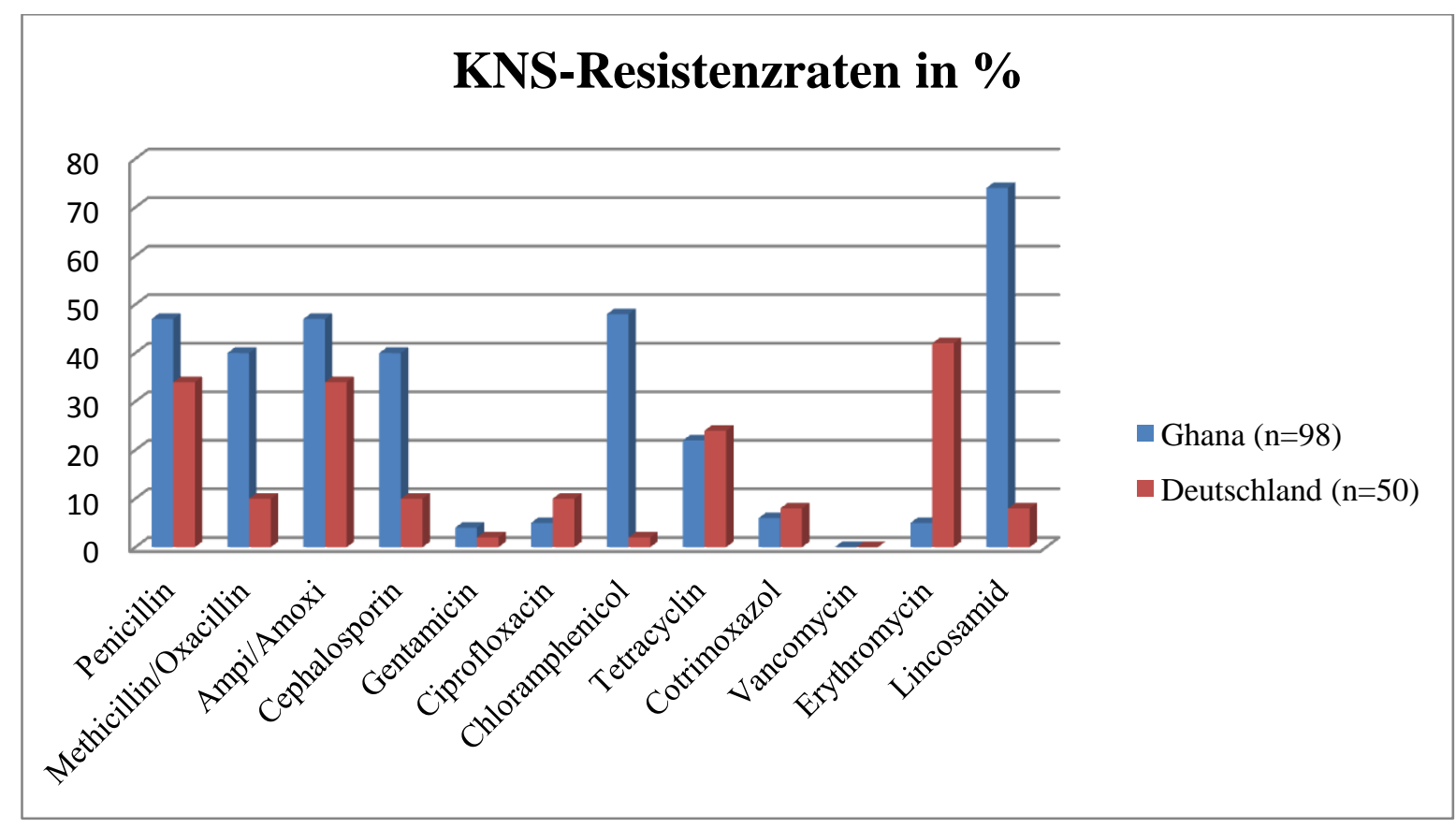

Abb.7: Komplettes Antibiogramm Koagulase-negativer Staphylokokken im Vergleich der Abstriche von Probanden aus Ghana und Deutschland 
Anders verhielt es sich bei S. aureus, wobei zwei der in Deutschland häufig angewandten Medikamente (Penicillin G, Ampicillin) in den deutschen Proben höhere Resistenzen zeigten. Der einzig signifikante Unterschied ergab sich allerdings für Chloramphenicol, gegen das die S. aureus-Isolate aus Ghana zu 47,1\% (n=16) resistent waren, wohingegen nur 6,3\% $(n=1)$ der Isolate aus den Proben der deutschen Kontrollgruppe resistent war (p-Wert <0,022) (siehe Abb.8).

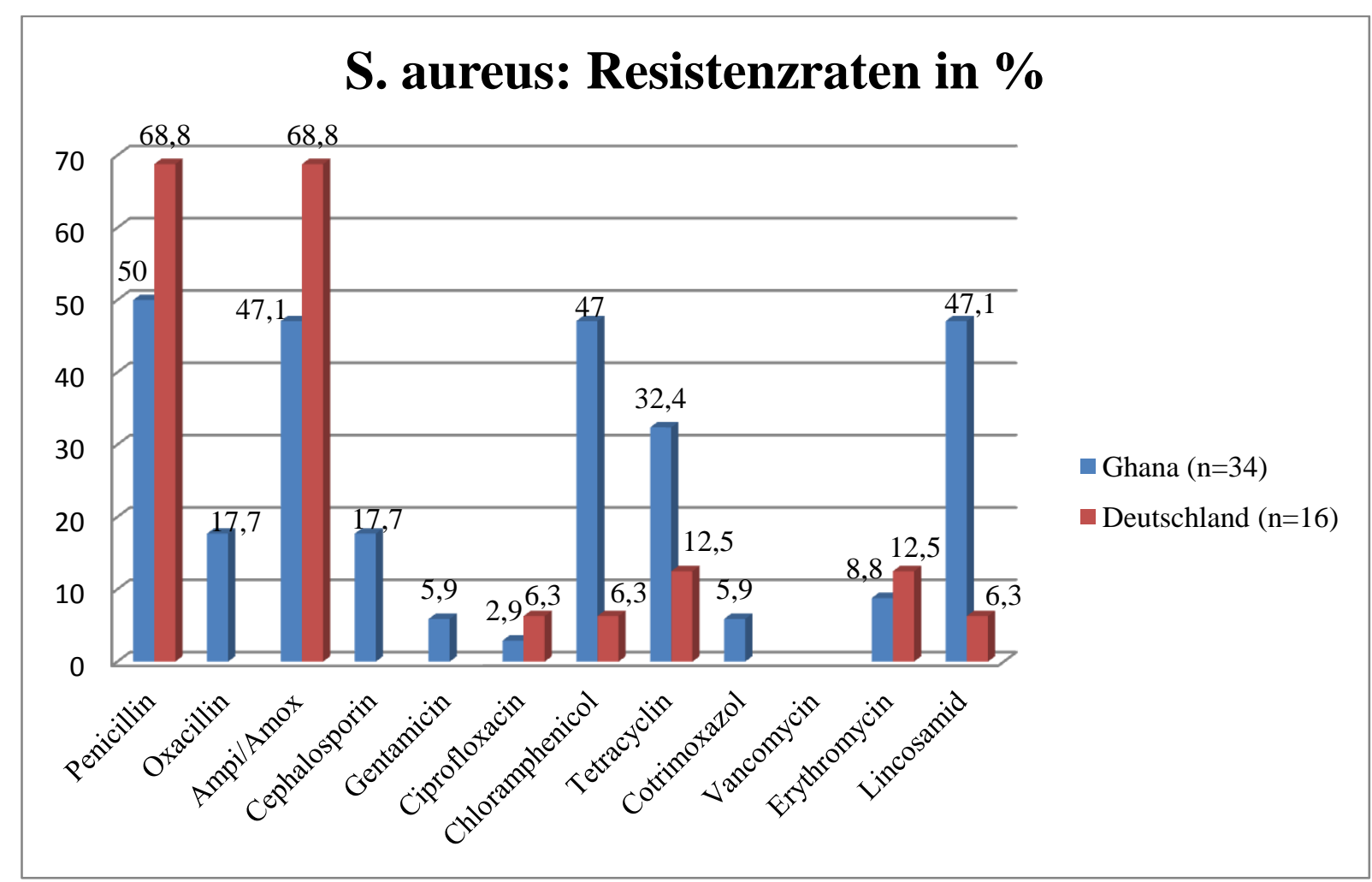

Abb.8: Resistenzraten von S. aureus in \% im Vergleich der Abstriche von Probanden aus Ghana und Deutschland

Auch im Hinblick auf andere Antibiotika gab es auffällige Unterschiede bezüglich der Resistenzlage der Bakterien. Die gramnegativen Bakterien wie z.B. Proteus und Enterobacter waren in den Abstrichen aus Deutschland kaum nachweisbar, aber auch hier fanden sich Unterschiede bei den Resistenzen. Wegen zu geringer Stichprobenzahlen im Vergleich mussten sie jedoch in Gruppen zusammengefasst werden: Es fanden sich keine signifikanten Unterschiede im Resistenzspektrum der Enterobacteriaceae (E.coli, Enterobacter, Proteus, Pantoea, Klebsiella und Citrobacter) beider Länder (siehe Abb.9) sowie Pseudomonas/Stenotrophomonas, diese werden gesondert aufgeführt (siehe Abb.10). 
Ergebnisse

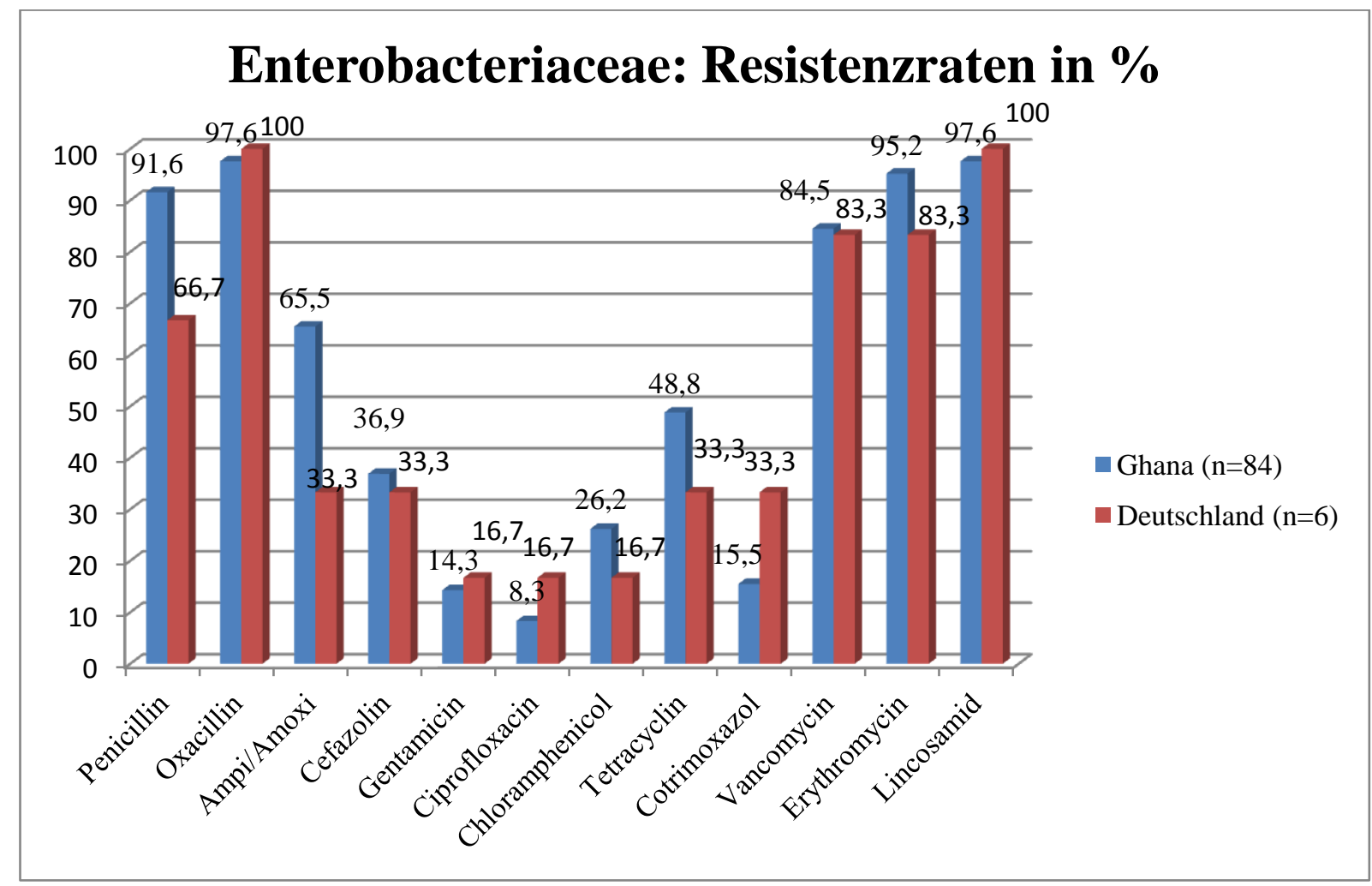

Abb.9: Resistenzraten der Enterobacteriaceae im Vergleich der Abstriche von Probanden aus Ghana und Deutschland

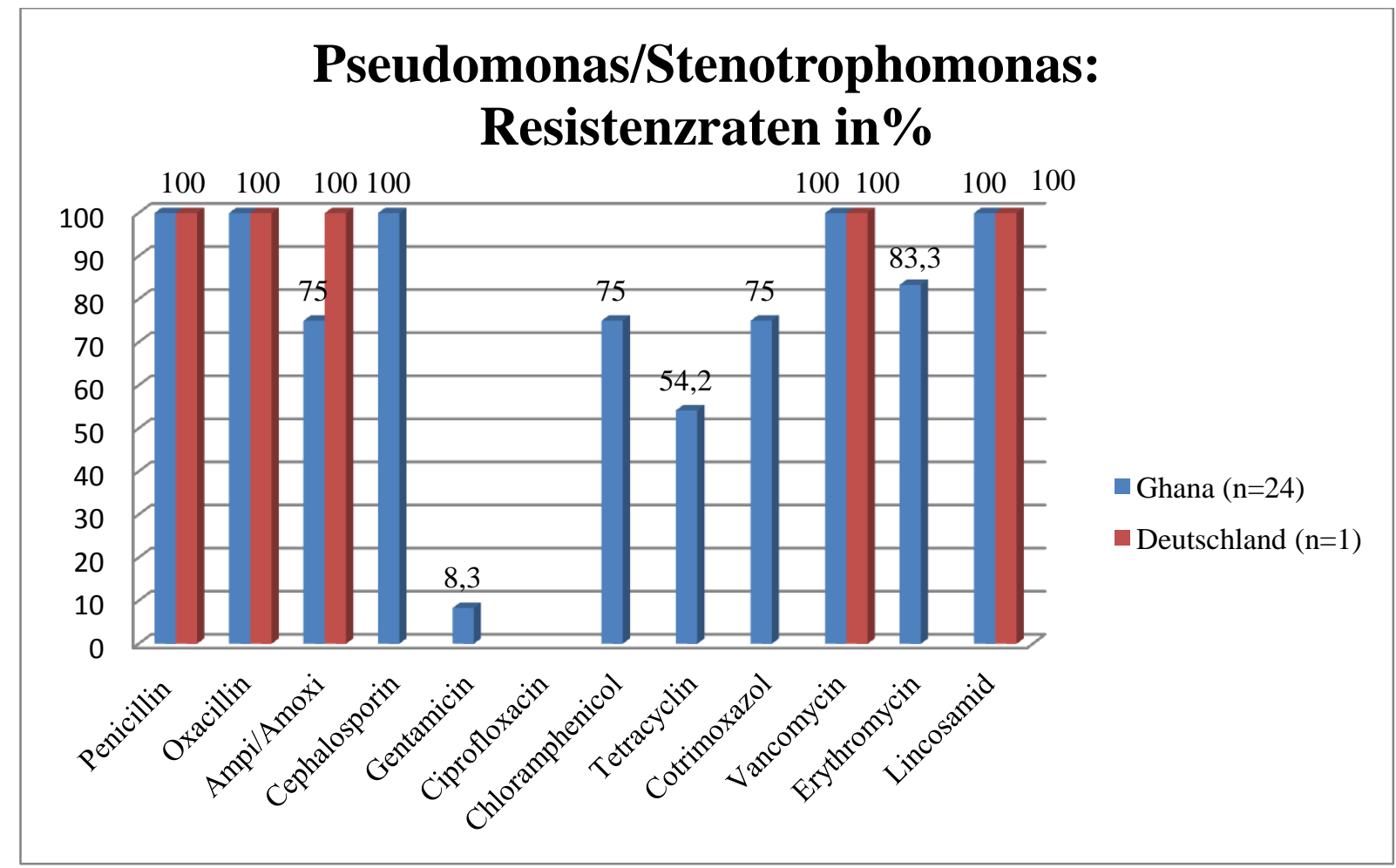

Abb.10 : Resistenzraten von Pseudomonas/Stenotrophomonas im Vergleich der Abstriche von Probanden aus Ghana und Deutschland 


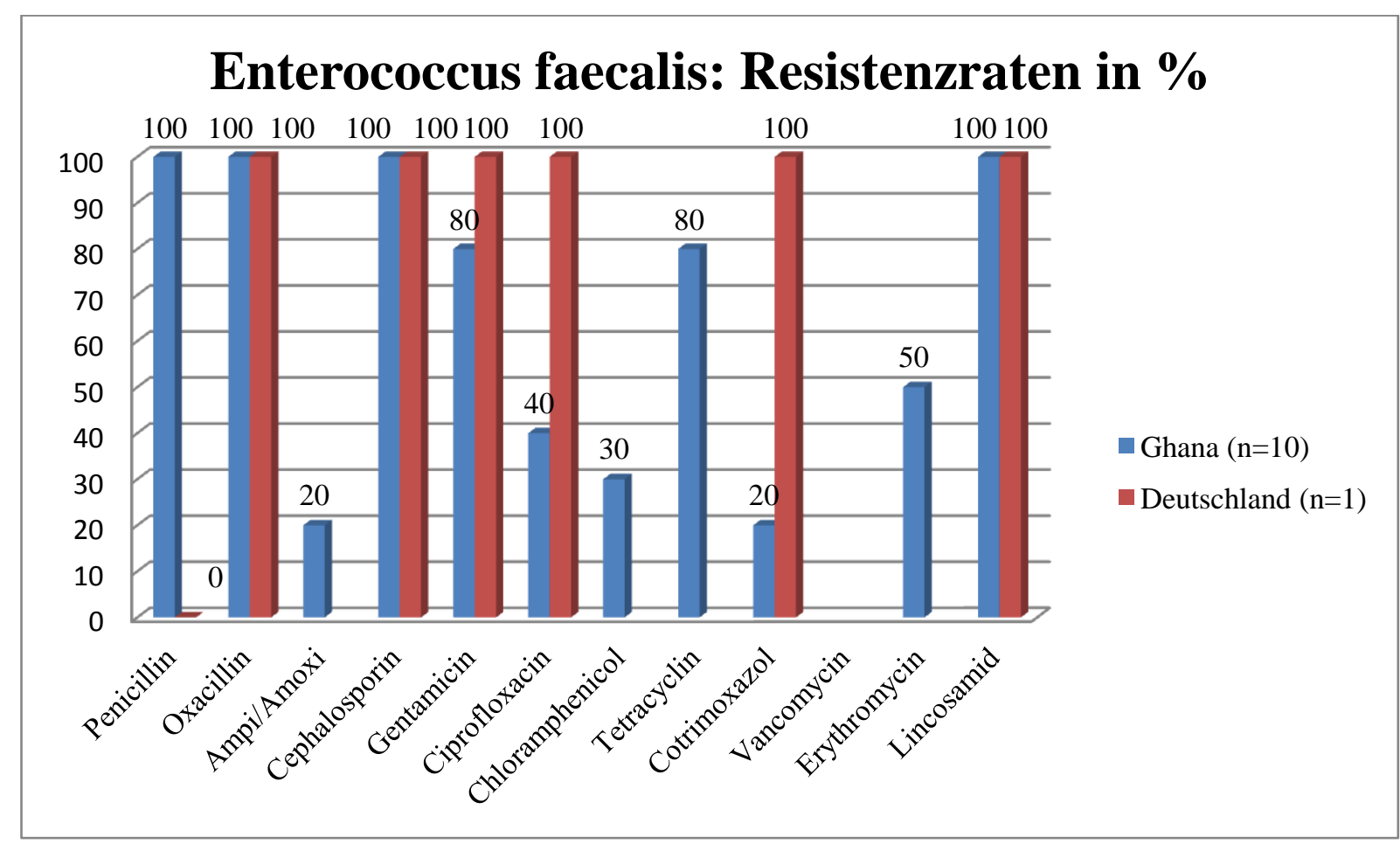

Abb.11: Resistenzraten von Enterococcus faecalis im Vergleich der Abstriche von Probanden aus Ghana und Deutschland

\subsection{Konkordanz zwischen der Anwendung von Antibiotika und Resistenzen}

Aus der Befragung der ghanaischen Probanden geht hervor, dass 44,0\% ( $n=88)$ von ihnen innerhalb der letzten 4 Wochen mindestens ein Antibiotikum erhalten hatten. Dabei wurden in 13,6\% Chloramphenicol, 52,3\% Amoxicillin oder Ampicillin, 25,0\% Tetracyclin, 3,4\% Penicillin, 4,5\% Metronidazol, 2,3\% Cloxacillin und 3,4\% Rifampicin eingenommen (siehe Abb.12). In wenigen Fällen gab es Mehrfachnennungen. Manche Antibiotika wurden nur einmalig oder über kurze Zeit eingenommen. Die Verabreichung von Penicillin erfolgte in Form von Spritzen, das Tetracyclin wurde zum Teil als Pulver direkt in Wunden gestreut. Laut Befrager würde in Ghana außerdem häufig Cotrimoxazol eingesetzt, das jedoch wegen der äußeren Form von den Einwohnern mit Paracetamol gleichgesetzt würde und somit nicht als Antibiotikum erkannt wurde und möglicherweise deshalb nicht in die Fragebogen-Statistik eingegangen ist. Es ergab sich nebenbei ein aufschlussreiches Bild zum Konsumverhalten von Antibiotika in der täglichen Praxis des Landes, in dem Chloramphenicol zum Zeitpunkt der Studie (nach Ampicillin und Tetracyclin) nach wie vor eines der am häufigsten eingesetzten Antibiotika war. 


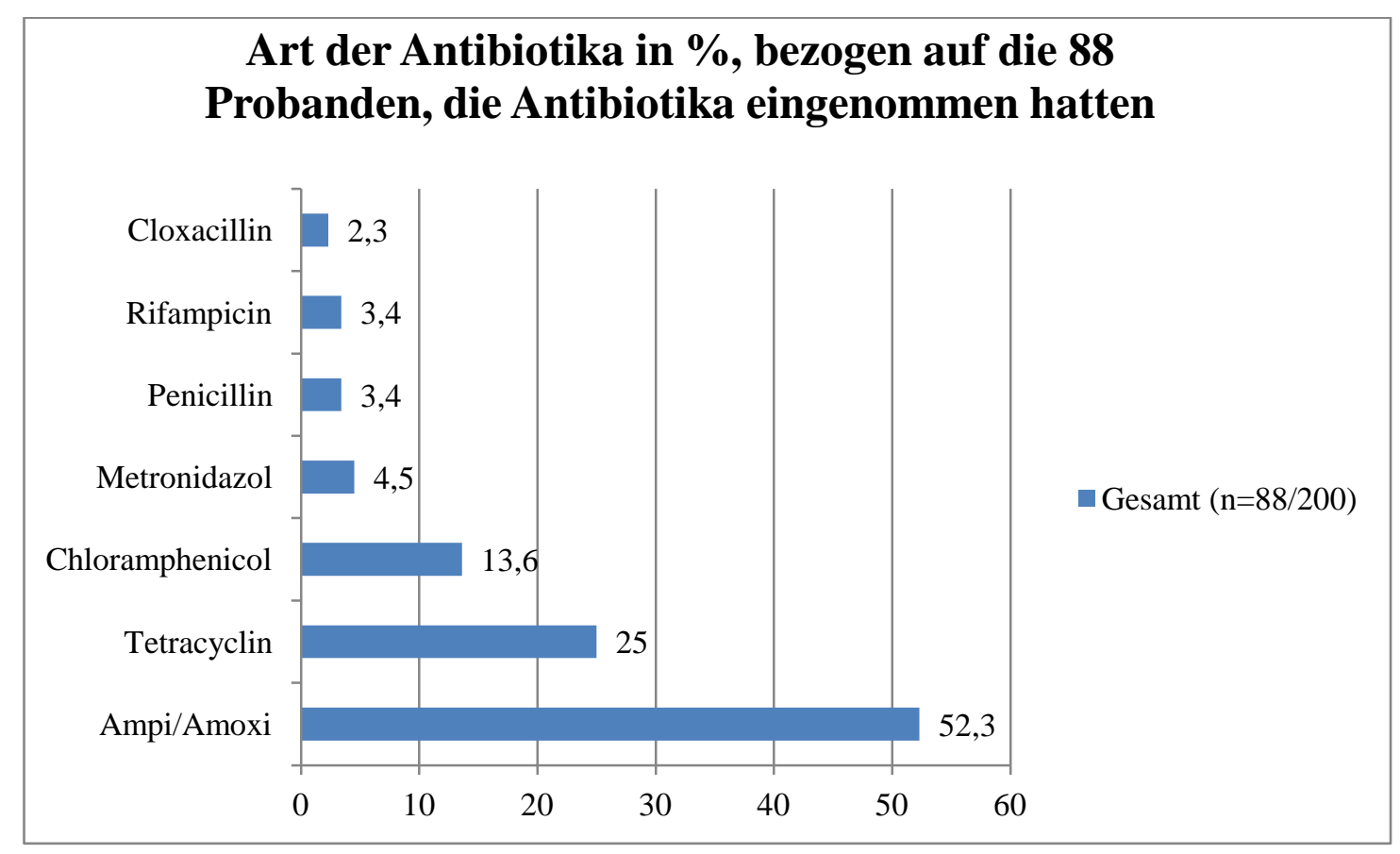

Abb.12: Art der Antibiotika, die von ghanaischen Probanden innerhalb der letzten 4 Wochen vor Probeentnahme eingenommen wurden

Im Gegensatz zu Ghana wird in Deutschland Chloramphenicol wegen seiner gefürchteten Nebenwirkungen schon seit vielen Jahrzehnten kaum noch systemisch eingesetzt, es wurde daher auch von keinem der deutschen Probanden eingenommen. Dies könnte die signifikanten Unterschiede bei den beobachteten Resistenzen erklären: In den Antibiogrammen der nachgewiesenen Bakterien finden sich bei den Abstrichen aus Deutschland bei den Staphylokokken Chloramphenicol-Resistenzen von 2\% (KNS) bis 6,3\% (S. aureus) (jeweils n=1). Im Gegensatz dazu wiesen 48,0\% der Staphylokokken aus Nasenabstrichen der ghanaischen Patienten eine Chloramphenicol-Resistenz auf $(n=48$; 17) (p-Wert <0,0001; pWert<0,0325). Die höchsten Resistenzraten gegenüber Chloramphenicol wiesen Pseudomonas/Stenotrophomonas aus den Abstrichen der ghanaischen Probanden mit 75\% auf. Wegen der geringen Anzahl dieser Bakterien in den Abstrichen des deutschen Kollektivs konnten diese Ergebnisse jedoch nicht ausreichend korreliert werden. Bei den anderen getesteten Bakterien fand sich in Deutschland eine 100\%-ige Sensibilität für Chloramphenicol, während die Resistenzrate in Ghana zwischen 20,0 und 50,0\% lag.

Auf der anderen Seite zeigten z.B. die aus den Abstrichen der deutschen Kontrollgruppe isolierten KNS signifikant höhere Resistenzraten gegen die teureren und in der Regel in Deutschland häufig angewandten Medikamente Ciprofloxacin, Tetracyclin und Erythromycin, nur für letzteres war der Unterschied signifikant (siehe Abb.6 und Abb.7). 


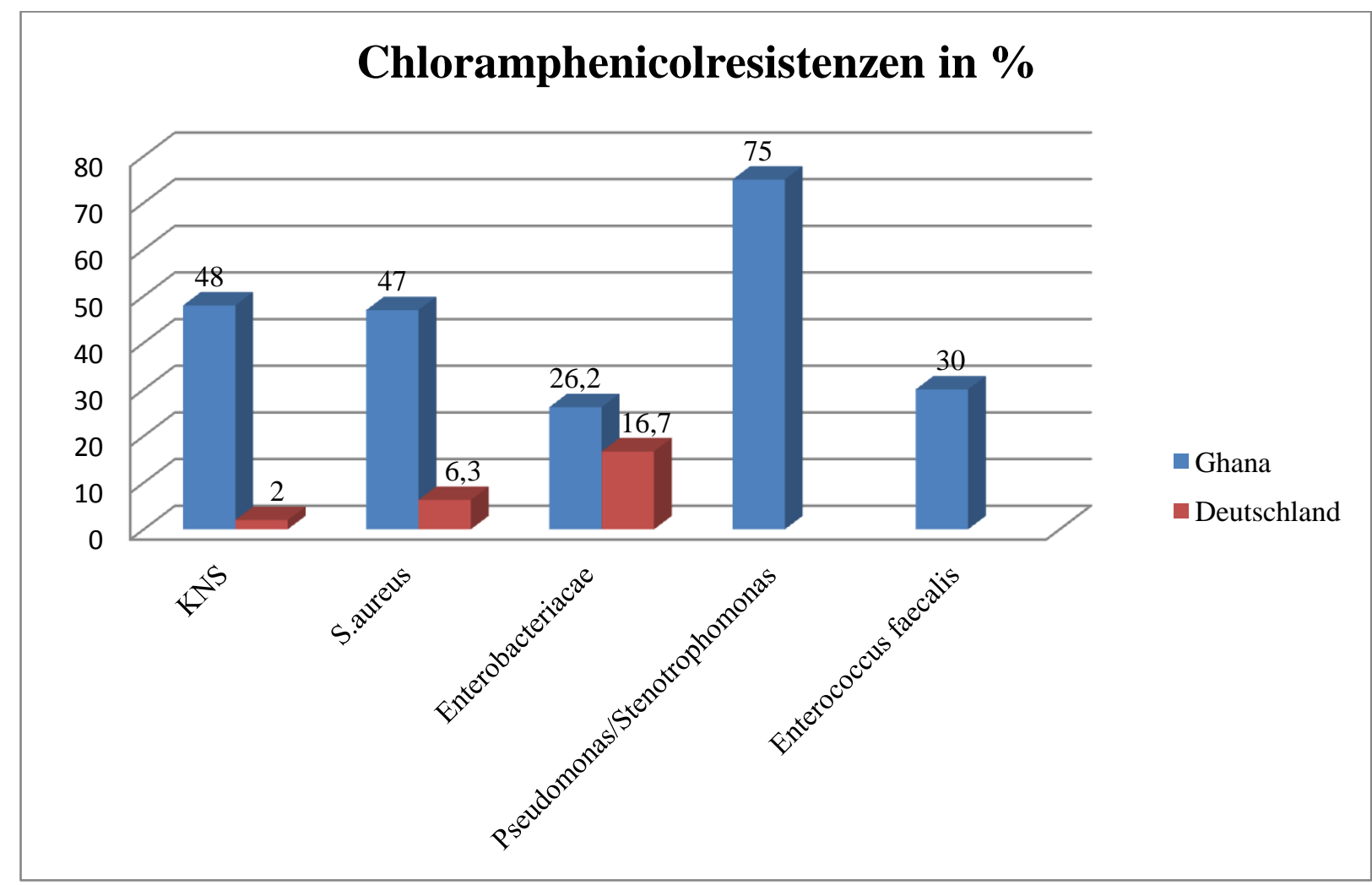

Abb.13: Signifikante Unterschiede der Chloramphenicol-Resistenzen im Vergleich der Flora der Abstriche aus Ghana und Deutschland

\subsection{MRSA im Vergleich Ghana - Deutschland}

Unter den 200 Abstrichen der ghanaischen Patienten befanden sich 33 Träger/ 35 Isolate von Staphylococcus aureus, von denen 6 resistent gegen Methicillin/Oxacillin waren. Das heißt 16,5\% der Abstriche enthielten S. aureus und insgesamt wurden 3\% MRSA nachgewiesen. Bezogen auf alle nachgewiesenen S. aureus Isolate betrug der MRSA-Anteil 17,7\%. Im Gegensatz $\mathrm{zu}$ diesen Ergebnissen wurde in 16 Abstrichen (19,0\%) der deutschen Kontrollgruppe ( $\mathrm{n}=84)$ S. aureus nachgewiesen, wobei alle Isolate Methicillin-sensibel waren. Das Vorkommen von Staphylococcus aureus als Bestandteil der transienten Nasenflora war also im Vergleich zwischen den Patienten aus Ghana und den Probanden aus Deutschland annähernd identisch, während die Methicillin-Resistenz in Ghana eindeutig häufiger zu finden war. Diese Stichproben sind jedoch zu klein, um ihnen eine statistische Signifikanz zuzuschreiben ( $\mathrm{p}$-Wert $<0,075)$. 
Ergebnisse

3.5 Fakultative Pathogenität des nasalen Bakterienreservoirs

Da die ghanaischen Abstriche in einem ambulanten Bereich abgenommen wurden, waren folglich die meisten der Probanden zum Zeitpunkt der Entnahme krank bzw. hatten einen Grund, sich in medizinische Behandlung zu begeben. Zur Übersicht über die Krankheitsverteilung siehe Abb.14

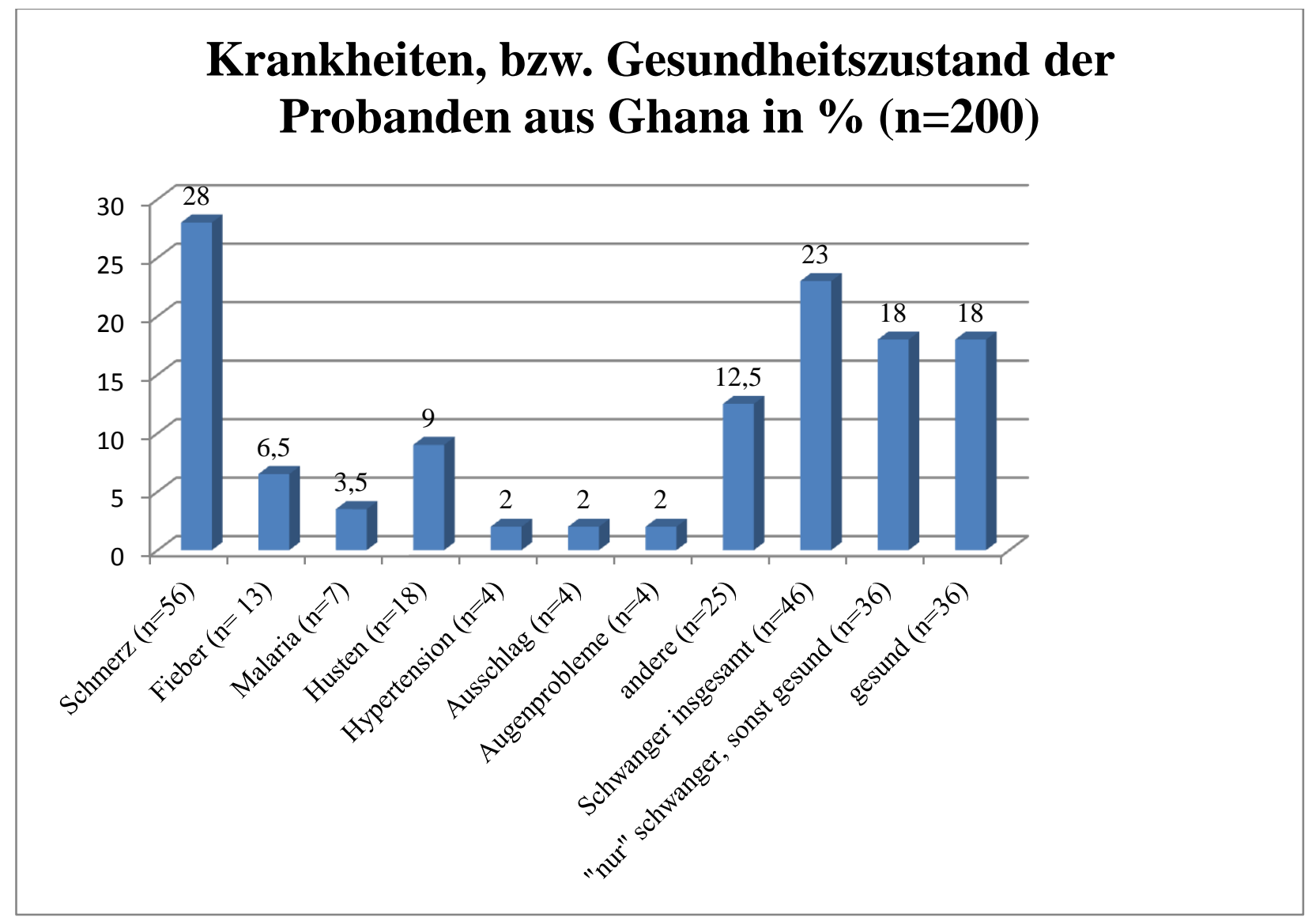

Abb.14: Prozentuale Verteilung der Gründe, die zur Vorstellung in der Poliklinik führten (Mehrfachnennungen möglich)

Der größte Teil der Patienten kam demnach mit Schmerzen verschiedener Lokalisationen $(28,0), 46,0 \%$ waren schwanger und 3,5\% hatten Malaria. Nur 9,0\% litten unter Husten und $6,5 \%$ kamen wegen eines fieberhaften Infektes.

Zumindest ein Teil der ghanaischen Probanden ist als immunreduziert anzusehen; ein weiterer Teil litt zudem an Erkrankungen des Respirationstraktes und könnte möglicherweise auch eine Besiedlung mit fakultativ pathogenen Bakterien in der Nase aufgewiesen haben. Von den 22 Patienten mit Symptomen von Atemwegserkrankungen (Husten, Ohrenschmerzen, Asthma, teilweise mit Fieber) waren in der Tat $16(72,7 \%)$ mit fakultativ pathogenen Keimen 
besiedelt, allerdings liegt der Anteil der pathogenen Besiedlung damit unter dem Durchschnitt der Abstriche von Probanden aus Ghana (82,5\%).

Sieben $(31,8 \%)$ der Patienten mit Symptomen einer Erkrankung des Respirationstraktes nahmen Antibiotika ein, davon hatten 3 Patienten keinen Nachweis fakultativ pathogener Bakterien. Zwei der Patienten hatten Rifampicin eingenommen, das nicht im Spektrum der hier getesteten Antibiotika enthalten war, da es in Deutschland als Reserveantibiotikum gilt. Die anderen beiden Patienten hatten Amoxicillin/Ampicillin eingenommen, die jeweils identifizierten Bakterien (Citrobacter, Enterobacter und Acinetobacter) waren dagegen resistent.

87 Probanden $(43,5 \%)$ hatten innerhalb der letzten 4 Wochen vor Entnahme des Abstriches Antibiotika eingenommen. Das sind signifikant mehr als in der deutschen Gruppe: Dort hatten $7,1 \%$ aller Probanden ( $\mathrm{n}=6)$ innerhalb der 4 Wochen vor Probeentnahme Antibiotika eingenommen ( $\mathrm{p}$-Wert $<0,0001)$.

Da die Abstriche der deutschen Kontrollgruppe auf einer öffentlichen Veranstaltung entnommen wurden, waren hier nur sporadisch Probanden leicht erkrankt. 57,1\% der Personen waren innerhalb des vergangenen Jahres gesund gewesen, etwa 32,0\% hatten einen grippalen Infekt oder Atemwegsinfekt durchgemacht (siehe Abb.15). 
Ergebnisse

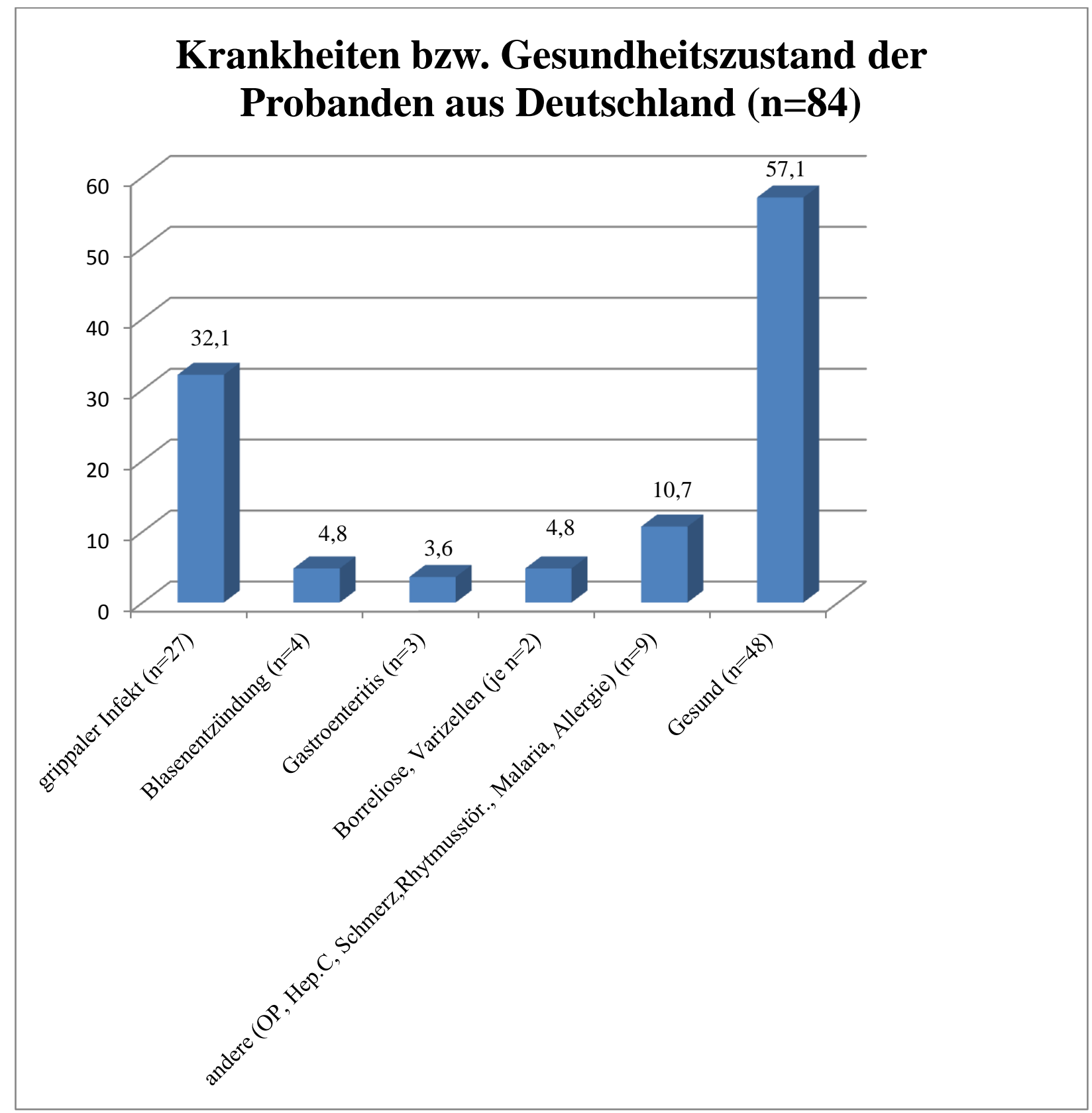

Abb.15: Krankheiten der deutschen Probanden innerhalb des Jahres vor Probeentnahme 
Ergebnisse

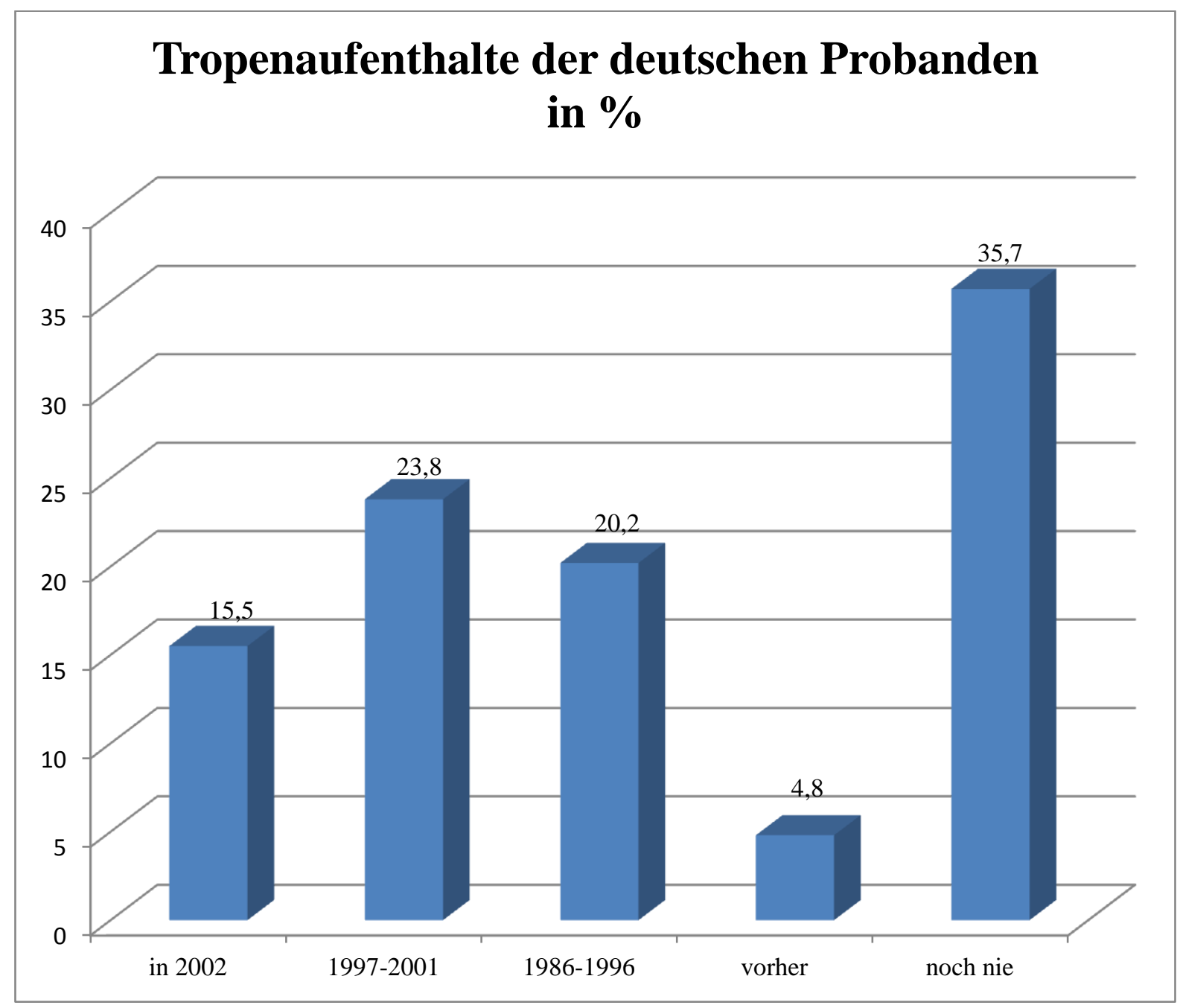

Abb.16: Tropenaufenthalte der deutschen Probanden vor Entnahme des Abstriches 


\section{Diskussion}

Diese Arbeit sollte die bakterielle Nasenflora und deren Antibiotikaempfindlichkeit in einem Probandenkollektiv aus Ghana mit der einer deutschen Kontrollgruppe vergleichen, eventuelle Unterschiede aufzeigen und die möglichen Hintergründe und Ursachen diskutieren. Während die geschlechtliche Korrelation der Probanden gut gelungen ist, zeigen sich im Bereich der Altersverteilung landesspezifische Unterschiede: Von den Probanden in Ghana waren fast 40,0\% zwischen 20 und 30 Jahre alt, in der deutschen Kontrollgruppe waren über die Hälfte der Personen über 40 Jahre. Das bedeutet, dass sich beide Populationen etwa in der Mitte ihrer natürlichen Lebenserwartung befanden (laut WHO in Ghana etwa 64 Jahre, in Deutschland 81 Jahre) (WHO 2013a, WHO 2013b).

Die Patienten- bzw. Probandenkollektive unterschieden sich dahingehend, dass die Ghanaer an einem definierten Tag in die Poliklinik eines Krankenhauses als Patienten gekommen waren, während die Proben des deutschen Kontrollkollektives auf einer Versammlung des Missionsärztlichen Institutes in Würzburg entnommen wurden, so dass diese nicht als Patienten betrachtet werden können. Daher variieren auch die Symptomenkomplexe sowie der vorangegangene Gebrauch von Antibiotika innerhalb der beiden Kollektive.

Da die Proben bei Patienten einer ambulanten Klinik in Ghana entnommen wurden, hatte der Großteil der Probanden eine aktuelle Erkrankung, war innerhalb des vergangenen Jahres krank gewesen oder suchte wegen einer Schwangerschaft den Arzt auf. Die Ursachen des Krankenhausbesuches der Ghanaer waren vielfältig und standen nur selten in Verbindung mit Infektionen der Atemwege oder anderen möglicherweise mit pathogener Bakterienbesiedlung in der Nase assoziierten Krankheiten (siehe Abb.14). Zudem wich die nasale Besiedlung der Patienten, die wegen Atemwegserkrankungen vorstellig wurden, nicht signifikant von der Besiedlung der anderen ghanaischen Patienten ab.

Die deutsche Kontrollgruppe wurde aus logistischen Gründen auf einer tropenmedizinischen Versammlung rekrutiert, was mehrere Störfaktoren begünstigte: Ein Großteil der deutschen Probanden war zum Zeitpunkt der Probeentnahme gesund. Zudem waren einige der Probanden bereits in afrikanische Länder - wie Ghana - gereist und viele der Probanden waren beruflich im medizinischen Bereich tätig. Diese Faktoren haben potentiell Einfluss auf die bakterielle kommensale Flora. Da jedoch nur knapp 14,0\% der Probanden im Zeitraum von maximal einem Jahr vor dieser Untersuchung in den Tropen gewesen waren und die meisten 
darüber hinaus keine aktuellen Krankheiten angaben, ist es unwahrscheinlich, dass diese Reisen ihre nasale Bakterienflora entscheidend verändert haben.

Im ghanaischen Untersuchungskollektiv fanden sich 35 Patienten mit Fieber, 23 mit Malaria und 22 mit Husten. 61 Patienten klagten über Schmerzen und 47 waren schwanger (Siehe Abb. 14). Außerdem kamen unspezifische Allgemeinsymptome wie Durchfall, Schwindel und Anämien vor, und einige Patienten hatten Vorerkrankungen wie Bluthochdruck, Diabetes mellitus, Hauterkrankungen oder „Herzprobleme“.

Bei den deutschen Probanden wurden Krankheiten innerhalb des vorangegangenen Jahres dokumentiert: 27 Probanden hatten innerhalb des Jahres vor Probeentnahme eine Infektion der Atemwege erlitten, 3 von ihnen hatten eine Erkrankung des Magen-Darm-Traktes durchgemacht. Es gab 4 Probanden mit Harnwegsinfekten innerhalb des vergangenen Jahres und je 2 mit Borreliose und Varizellen sowie eine Malariaerkrankung. 9 Probanden hatten andere Beschwerden (wie Herzrhythmusstörungen, Kopf- bzw. Knieschmerzen, Allergien oder Operationen und eine Hepatitis C) gehabt. 48 Probanden sagten von sich selbst, sie seien innerhalb des vergangenen Jahres gesund gewesen (siehe Abb.15). Da viele Probanden dem Missionsärztlichen Institut angehörten, waren einige von ihnen in den letzten Jahren in den Tropen gewesen (siehe Abb.16).

Von den 200 untersuchten Ghanaern hatten 87 innerhalb von vier Wochen vor der Probenentnahme Antibiotika eingenommen, 10 nahmen sie noch zum Zeitpunkt der Materialgewinnung ein. Am häufigsten wurde Amoxicillin bzw. Ampicillin verabreicht (siehe Abb.12). Die deutschen Probanden hatten nur zu 7,1\% in den vorangegangenen 4 Wochen Antibiotika eingenommen.

Die Erhebung der Daten von der Entnahme des Abstriches über das Anzüchten der Keime bis zur Differenzierung und Erstellung der Antibiogramme wurde gemäß allgemeinen Laborstandards durchgeführt. Im Gegensatz dazu sind bei der Materialgewinnung sowie der Verarbeitung der Proben an verschiedenen Stellen potentielle Störfaktoren zu berücksichtigen: Obwohl sämtliche Abstriche von demselben Untersucher ausgewertet wurden, könnten dennoch unterschiedliche methodische Aspekte einen Einfluss auf die Ergebnisse gehabt haben. Zum einen wurden die Nasenabstriche nach kurzer Einweisung von verschiedenen Mitarbeitern und Helfern entnommen, die möglicherweise bei den Entnahmetechniken voneinander abwichen. Die Abstriche wurden aus einem Nasenloch entnommen und als repräsentativ für die Nasenflora angesehen, auch wenn sie eventuell von unterschiedlichen Stellen und in unterschiedlicher Tiefe entnommen wurden. Der Vorteil 
dieser Methode ist die Repräsentanz der klinischen Methode zur Bestimmung von Mikroorganismen, da auch im Praxisalltag unterschiedliche und individuelle Entnahmeverfahren angewendet werden.

Ein weiterer Störfaktor ist der Transport der ghanaischen Proben über mehrere Tage bei nicht immer gewährleisteter Kühlkette. Dadurch mag es z.B. zu einer sekundären Kontamination mit Bacillus spp. und möglicherweise auch mit Schimmelpilzen gekommen sein. Diese werden deshalb in den Studienergebnissen nur am Rande diskutiert.

Zu erwähnen ist auch der unterschiedliche Zeitrahmen, in dem die beiden Gruppen untersucht wurden: Da es sich in der ghanaischen Gruppe um die doppelte Anzahl von Probanden handelte, dauerte die Evaluation der Abstriche entsprechend länger. Einzelne Ergebnisse mögen von der unterschiedlich langen Aufbewahrungsdauer der Proben beeinflusst worden sein.

Der Nachweis der Bakterien erfolgte rein qualitativ. Es gab durchaus Fälle, in denen 4 oder 5 verschiedene Bakterienarten in einem Abstrich gefunden wurden. Dies zog Herausforderungen bei der Isolation der einzelnen Keime nach sich und kann unter Umständen zur Überwucherung der langsamer wachsenden Isolate durch schneller wachsende Bakterienarten geführt haben. Es erfolgte keine Anreicherung der Bakterien in speziellen Nährmedien, so dass möglicherweise bestimmte, labilere Bakterien gar nicht nachgewiesen wurden. Außerdem wurden die Abstrichtupfer nur auf drei verschiedenen Agarplatten ausgestrichen, mit denen nicht alle potentiell möglichen Keimarten erfasst werden konnten (z.B. Meningokokken, Pneumokokken, Haemophilus influenzae).

Obwohl die meisten Keime bis zur Subspezies differenziert wurden, wird mit Ausnahme der Staphylokokken der Übersicht halber nur die Gattung angegeben. Diese Studie sollte einen Überblick über fakultativ pathogene und apathogene, kommensale Bakterien in der Nasenhöhle geben. Aus Gründen der Stichprobenanzahl wurden zur Betrachtung der Antibiogramme teilweise artverwandte Bakterien zusammengefasst, da man sonst keine statistisch signifikanten Aussagen hätte machen können.

Zum Fragenkatalog ist zu sagen, dass die Fragen von den unterschiedlichen Befragern auch verschieden detailliert gestellt wurden. Ein größeres Problem war die Befragung der Probanden bezüglich der Antibiotika, da die Medikamente in Ghana nicht unter dem Handelsnamen, sondern als rote, gelbe und schwarze Pillen bekannt sind. Dies führte bei der Auswertung zu Irritationen, zumal einige Probanden von nicht bekannten Farbkombinationen sprachen. Darüber hinaus wurde klar, dass manche Patienten die Antibiotika nur einmalig 
eingenommen hatten bzw. die Anwendung nicht entsprechend dem Standard geschah. Dadurch ermöglicht die Arbeit jedoch im Nebeneffekt auch einen Einblick über den ungezielten Einsatz der Antibiotika in Ghana, da es offensichtlich kaum mehr als 5 verschiedene Wirkstoffe gibt, die relativ unspezifisch bei jeder Art von Infektion eingesetzt werden (Bosu und Ofori-Adjei 1997b). In Deutschland konnten die meisten Probanden das verabreichte Präparat hingegen genau benennen.

Keimspektrum und Antibiogramm

Siebzehn der Abstriche der deutschen Kontrollgruppe zeigten gar kein Keimwachstum; dies ist am ehesten auf Abnahme- oder Auswertungsfehler zurückzuführen, daher wurden diese Ergebnisse nicht in die Gesamtauswertung mit einbezogen. In der Routinelabordiagnostik kommen nur sehr selten sterile Nasenabstriche vor.

Ingesamt wurde in der ghanaischen und der deutschen Kohorte in jeweils über der Hälfte der Abstriche eine Nasenflora identifiziert, die vorwiegend aus apathogenen Bakterien bestand. Die Nasenflora der Probanden der beiden Gruppen unterschied sich hinsichtlich der Zusammensetzung jedoch wie folgt: Die Ghanaer wiesen wesentlich mehr fakultativ pathogene Erreger in ihrer Nasenflora auf, wobei vor allem für Pseudomonas/Stenotrophomoas und anderen Non-Fermenter, Enterobacter Citrobacter und Klebsiellen signifikante Unterschiede feststellbar waren. Insgesamt war der Nachweis fakultativ pathogener Keime in den Proben aus Ghana mehr als doppelt so häufig, wie der in den Abstrichen der deutschen Kontrollgruppe. Auffällig ist dabei der hohe Anteil an gramnegativen Bakterien (größtenteils Enterobakterien) in den Proben aus Ghana.

Aus afrikanischen Studien fanden sich folgende Vergleichswerte: Ndip et al. fanden bei Patienten mit Otits media zu 41,0\% S. aureus, der zu 21,1\% resistent gegen Penicillin sowie zu 96,2\% und 98,1\% resistent gegen Erythromycin und Chloramphenicol (Ndip et al.1995) war. In dieser Studie fand sich nur bei einem ghanaischen Probanden mit Atemwegsinfekt Staphylococcus aureus, die Gesamtzahl der nachgewiesenen S. aureus war zu 50,0\% Penicillin-resistent, zeigte jedoch nur $\mathrm{zu} 47,5 \%$ und $1,5 \%$ Resistenzen gegen Chloramphenicol und Erythromycin. Ohene analysierte 199711.380 Bakterienisolate aus verschiedenen Materialien (Blut, Urin, Sputum, HNO-Abstriche, Aspirate, sonstige Sekrete) in Ghana. Es fanden sich 47,1\% E. coli, 16,8\% Pseudomonas und 14,6\% Proteus. Im Bereich der Atemwege wurden in den untersuchten Materialien $\mathrm{zu} 17,1 \%$ S. aureus, $11,0 \%$ 
Koagulase-negative Staphylokokken, 6,7\% B-Stroptokokken, 14,0\% E.coli und 11,7\% Proteus, 9,8\% Klebsiellen und 2,0\% Pseudomonas nachgewiesen (Ohene 1997).

In der vorliegenden Arbeit wurden in den Abstrichen ghanaischer Probanden in 17,0\% Staphylococcus aureus, in 1,0\% E. coli, 5,0\% Proteus und 7,0\% Klebsiellen sowie in 12,0\% Pseudomonas/Stenotrophomonas nachgewiesen. Wolf et al. verglichen 1999 die Nasopharyngealflora von unter 5-jährigen Kindern aus Brasilien, den Niederlanden und Angola. Enterobacteriaceae und Non-Fermenter wurden bei den Kindern aus Brasilien zu $50,0 \%$, in Angola zu 57,0\% und bei den Kindern aus den Niederlanden nur zu 4,0\% in der Flora des Nasopharynx gefunden (Wolf et al. 1999). In der vorliegenden Arbeit wurden in der Nasenflora ghanaischer Patienten 65,5\% Enterobacteriaceae und Non-Fermenter nachgewiesen, bei den Abstrichen der Probanden aus Deutschland waren es 25,0\%. Eine Studie aus dem Kongo untersuchte die häufigsten Erreger kindlicher eitriger Otitis media und fand ebenfalls vorwiegend Pseudomonas (22,0\%), Proteus (23,0\%) und Citrobacter $(20,0 \%)$ (Nyembue et al. 2003).

Aus der Erhebung der Gründe für die Vorstellung in der Poliklinik - in Korrelation mit der Keimverteilung - ergibt sich, dass man bei nur bei 9,0\% der ghanaischen Probanden von einen unmittelbaren Einfluss ihres Gesundheitszustandes auf die Zusammensetzung der nasalen Flora ausgehen muss (siehe Abb. 14 und 15). Die meisten Patienten (insgesamt nahezu $50,0 \%$ ) suchten wegen einer bestehenden Schwangerschaft oder unklaren Schmerzen den Arzt auf.

Die naheliegendste Erklärung für den im Vergleich zur deutschen Kohorte hohen Nachweis von Enterobakterien in den Abstriche aus Ghana ist die unterschiedliche Toilettenhygiene der beiden Länder; aber auch das Klima und viele andere Einflussfaktoren können eine Rolle gespielt haben.

Eine nigerianische Studie untersuchte die hygienischen Bedingungen in Kindertagesstätten und deckte zahlreiche Verunreinigungen insbesondere mit S. aureus und Enterobakterien wie E. coli, Klebsiella spp., Citrobacter spp. und Proteus mirabilis auf. Einige dieser Erreger wurden auch an den Händen der Kinder und im Trinkwasser gefunden (Itah und Ben 2004).

Da sich die bakterielle Besiedlung der Nase von Probanden in Ghana und Deutschland in dieser Studie signifikant unterscheidet, muss davon ausgegangen werden, dass auch hier exogene Faktoren wie Klima, Hygiene, Wasserversorgung und andere Umwelteinflüsse und Lebensumstände die Bakterienflora moduliert haben. Dies bestätigen auch zahlreiche weitere 
Studien, sowohl in Europa als auch in Afrika. So zeigten Kinderuntersuchungen in luftverunreinigten Gebieten im Rhein-Main-Gebiet eine Änderung der physiologischen Standortflora durch verschiedene Umweltfaktoren sowie rezidivierende Infekte durch eine Dauerbesiedlung des Nasen-Rachenraumes mit pathogenen Keimen (Beck und Schmidt 1987). In einer Studie von Felmingham et al. 1996 fanden sich regionale Unterschiede in der Sensibilität gegenüber Antibiotika zwischen Birmingham und Bristol in England. Eine Studie von Hofmann 1990 zeigte, dass soziologische Einflussfaktoren und exogene Belastungen, wie Industrieabgase, Ernährung, Wohnverhältnissen etc. zu einer unterschiedlichen Anfälligkeit für Atemwegsinfekte bei gleicher Bakterienbesiedlung führen können. Laut der Autoren führt eine chronische Exposition gegenüber Umweltverunreinigungen zur Störung des rhinobronchialen Reinigungssystems und damit potentiell zu vermehrtem Auftreten von Infekten. Afrikanische Studien zeigen vermehrte Ausbrüche von bakteriellen Infektionen in bestimmten klimatischen oder saisonalen Phasen, z.B. eine erhöhte Inzidenz bakterieller Meningitiden während der Trockenzeit in der Subsahara-Region (Mackie et al. 1992). Okolo zeigte 1986, dass eine fäkale Kontamination bei der Schlachtung von Nutztieren zu einem Transfer resistenter E. coli-Stämme führen kann. Diese Resistenzen können auf die menschliche Darmflora transferiert werden.

Wenn man gegenüber deutschen Städten rurale ghanaische Verhältnisse betrachtet, in denen $2008 \mathrm{zu}$ 14,3\% der Kinder unter 5 Jahren mangelernährt waren, 28,6\% in der Entwicklung verzögert und bis zu einem Viertel der Bevölkerung keinen Zugang zu sauberem Trinkwasser hatte, so liegt die Annahme nahe, dass auch diese Faktoren einen relevanten Einfluss auf die Besiedlung der Schleimhäute haben können. Die Toilettenhygiene, die in der Regel ohne Toilettenpapier und nur mit Wasser vollzogen wird, ist ein weiterer potentieller Faktor, der die natürliche Flora beeinflussen könnte (Alban et al. 2000). Diese These wird durch o.g. Ergebnisse insofern bestätigt, als dass die hohe Rate an Darmbakterien bei den ghanaischen Probanden mit den hygienischen Verhältnissen unmittelbar in Verbindung zu bringen ist.

$\mathrm{Da}$ es in Afrika gerade bei Kindern häufig zu tödlich verlaufenden Pneumonien durch gramnegative Darmbakterien kommt, erscheint eine ausgeweitete Aufklärung über Körperund Toilettenhygiene als mögliche einfache Strategie zur Reduktion der Infektionen (Wolf et al. 1999).

Über die Keimunterschiede hinaus ließen sich relevante Diskrepanzen bezüglich der Resistenzlage nachweisen, die mit dem Gebrauch von Antibiotika korrelierbar sind. 
Ansonsten konnten nur bei den KNS (hohe Stichprobenzahl) signifikante Unterschiede in der Sensitivität für Antibiotika nachgewiesen werden. Auch sie waren in den Proben aus Ghana resistenter gegen Chloramphenicol, jedoch waren die Resistenzraten gegen Ciprofloxacin und Tetracyclin in Deutschland deutlich höher. Besonders Ciprofloxacin, das zum Zeitpunkt der Datenerhebung in Ghana noch nicht erhältlich war, wird auch heute noch in Deutschland häufiger als in Ghana verwendet.

Konkordanz zwischen der Anwendung von Antibiotika und Resistenzentwicklung

Der Umgang mit bestimmten Antibiotika in der menschlichen Therapie, wie auch in anderen Bereichen (z.B. der Tiermast, Tierhaltung und Verarbeitung von Nutztieren) ist ausschlaggebend für die Entwicklung von Resistenzen bei verschiedenen Bakterien. Eine Studie von Wanyenya et al. 2004 zeigte, dass es in Uganda bei der Verarbeitung von Geflügel aufgrund mangelnder Hygiene regelmäßig zu Campylobacter „Cross-contamination“ durch die Bakterienpersistenz auf Küchenoberflächen kam. Okolo et al. hatten bereits 1986 gezeigt, dass auch die Tierhaltung in Afrika eine verbreitete Quelle für bakterielle Verunreinigungen und die Verbreitung von Resistenzen darstellt. Selbst die Verbreitung multipler Resistenzen durch Kuhmilch oder Fleischverzehr konnte nachgewiesen werden. Laut Manie et al. 1999 wurden zum Veröffentlichungszeitpunkt in den USA jährlich etwa 7,5 Mio. Tonnen Antibiotika in der Landwirtschaft verbraucht. Es wurde vor dem Lateraltransfer und der Selektion Vancomycin-resistenter Staphylokokken gewarnt. Basierend auf zahlreichen Studien und klinischen Untersuchungen lässt sich die These postulieren, dass je mehr und je unkritischer ein Antibiotikum eingesetzt wird, desto höher die Resistenzentwicklung der Bakterien gegen das entsprechende Antibiotikum sein wird. Das Verschreibungsverhalten bzw. der Umgang mit Antibiotika sowohl in Industrieländern als auch im ländlichen Afrika ist nach wie vor oft unkritisch und ungezielt. Zudem werden durch schlechtes Gesundheitsmanagement und falsche Anwendung Ressourcen verschwendet (Benbachir et al. 2001, Bosu und Ofori-Adjei 1997a, Bosu und Ofori-Adjei 2000, Brink et al. 2004, Harbarth et al. 2002, Kesah et al. 2003, Ritter et al. 1990).

Bereits die einmalige Therapie mit einem Antibiotikum, wie in unserer Befragung mehrfach aus Ghana berichtet, kann zur Resistenzentwicklung führen (Berg et al. 2004, Bosu und Acquah 1996). 
In dieser Studie fällt auf, dass die Bakterien für häufig eingesetzte Antibiotika verhältnismäßig hohe Resistenzraten aufwiesen. Laut einer Studie zu neonatalen Infektionen in Ghana hat die Resistenzrate von Klebsiella und Enterobacter gegen häufig angewandte Aminoglycoside und Cephalosporine von 20,0\% 1991/92 auf 65,0\% 2001/02 zugenommen. Die Autoren weisen darauf hin, dass diese gramnegativen Bakterien die häufigsten Erreger neonataler Infektionen in Ghana sind (Enweronu-Laryea und Newman 2007).

Eine Untersuchung in Ghana zeigte ebenfalls hohe Resistenzraten bei enterischen Bakterien. Die Proben wurden von Kindern im Alter von 1-4 Jahren mit und ohne Durchfall entnommen. Von den 318 untersuchten E. coli-Isolaten waren 81,0-91,0\% resistent gegen Ampicillin, 76,0-88,0\% gegen Trimethoprim/Sulfamethoxazol und 41,0-46,0\% gegen Chloramphenicol (Djie-Maletz et al. 2008). Gegen Antibiotika (hier Ofloxacin und Neomycin), die in Westafrika wenig eingesetzt werden, fanden sich wiederum hohe bakterielle Empfindlichkeiten von 90,0-100,0\% (Nyembue et al. 2003), was den Ergebnissen dieser Studie entspricht.

Eine konkrete Korrelation zwischen Erkrankungen der Probanden bei der ärztlichen Vorstellung, Antibiotikaeinnahme und Bakterienspektrum der Nasenhöhle und Resistenzen konnte in dieser Studie aufgrund zu geringer Fallzahlen nicht gezeigt werden.

Im globalen Interesse sollten zur Vermeidung von Epidemien mit multiresistenten Erregern entscheidende Veränderungen im Umgang mit Antiinfektiva vorgenommen werden.

Eine neue Strategie in der Bekämpfung fortschreitender Resistenzentwicklung ist es, auf ältere Antibiotika wieder zurückzugreifen, statt immer neue, kostspielige Medikamente zu entwickeln. So postuliert eine griechische Veröffentlichung, dass ältere Antibiotika (z.B. Polymyxine, Cotrimoxazol, Fosfomycin und andere), die nach längerer Karenzphase wieder eingesetzt werden, ein hohes Potential in der Therapie auch schwer $\mathrm{zu}$ behandelnder Infektionskrankheiten darstellen (Falagas et al. 2008).

Besonders anschaulich ist das Resistenzverhalten am Beispiel von Chloramphenicol nachzuvollziehen: Dieses Medikament nimmt insofern eine Sonderrolle ein, als es in den vergangenen 30 Jahren in westlichen Industrienationen kaum noch zum Einsatz gekommen ist, während es in afrikanischen Ländern wegen seiner Kostengünstigkeit zum Zeitpunkt dieser Studie noch immer zur Standardtherapie von Infektionen gehörte. Daraus ergibt sich hierzulande für die Bakterien eine längjährige Chloramphenicolkarenz, die sich in dieser Arbeit zumindest durch die In-Vitro signifikant höhere Sensibilität der Bakterien gegenüber diesem Antibiotikum widerspiegelt. 
Auch andere Studien kommen zu dem Ergebnis, dass ein Anwendungsstopp über einen definierten Zeitraum die Wirksamkeit etablierter Antibiotika wieder erhöhen könnte (De Souza et al. 1988).

Aus der Befragung unserer Probanden aus Ghana geht hervor, dass Chloramphenicol in Ghana zum Zeitpunkt dieser Studie noch immer ein häufig eingesetztes Antiinfektivum war. So war es 2001 laut nationaler Richtlinie noch Mittel der Wahl zur Behandlung von Typhus in Ghana (Gross et al. 2009). In den Antibiogrammen der nachgewiesenen Bakterien fanden sich bei den Abstrichen aus Deutschland lediglich bei den Staphylokokken ChloramphenicolResistenzen von 2,0 bis 6,3\%. Diese lagen bei den Ghanaern bei 47,0 bis 48,0\%. Bei einem Proteus-Stamm wurde eine Chloramphenicol-Resistenz nachgewiesen. Sämtliche anderen bei den deutschen Teilnehmern nachweisbaren Bakterien waren zu 100,0\% sensibel gegenüber Chloramphenicol, während die Chloramphenicol-Resistenzrate in Ghana zwischen 26,2 und $75,0 \%$ lag.

In den meisten Industriestaaten wurde Chloramphenicol mittlerweile zurückgezogen und hat hier nur noch historische Bedeutung (Brodt 2013). Nur im Rahmen von Unverträglichkeitsreaktionen gegen andere Antibiotika kommt es in Einzelfällen von einigen wenigen Erkrankungen wie komplizierter Meningitis und lebensbedrohlichen intraokulären Infektionen oder Hirnabzessen wegen seiner guten Liquorgängigkeit noch zum systemischen Einsatz. Eine systemische Verabreichung ohne ausreichende Indikation oder mit Überschreiten der zulässigen Gesamtdosis für Erwachsene (25-30 g) wird als Kunstfehler angesehen (Brodt 2013). Es eignet sich jedoch gut zur Lokalbehandlung von Augeninfektionen, weil dabei keine systemische Verteilung stattfindet. Strenge Kontraindikationen für die Anwendung von Chloramphenicol sind aplastische Bluterkrankungen, schwere Leberinsuffizienz mit Ikterus sowie Schwangerschaft und Stillzeit. Die Nebenwirkungen des Chloramphenicol sind vielfältig und gefürchtet. In 1: 10.000 bis 40.000 Fällen kommt es zu aplastischen Anämien oder Panzytopenien, die in 50,0\% der Fälle tödlich verlaufen. Eine häufige Nebenwirkung sind Neuritiden, vor allem die Neuritis nervi optici sowie periphere Nervenentzündungen. Selten kommt es zu gastrointestinalen Beschwerden, die meist gutartig verlaufen (Brodt 2013).

Bei Kindern, vor allem im Neugeborenenalter, aber auch bei Kleinkindern kann es durch die unreife Leberfunktion und die dadurch verminderte Glukuronidierung oder durch Überdosierung zur Kumulation von Chloramphenicol kommen. Der daraus resultierende Symptomenkomplex aus Hypothermie, Verdauungsstörungen, Atemstörungen, grauem 
Hautkolorit, unbeherrschbarem Kreislaufkollaps und Todesfolge, ist unter dem Namen GraySyndrom bekannt (Brodt 2013).

Als hitzebeständiges, stabiles und billiges Antibiotikum spielt Chloramphenicol in den Tropen nach wie vor eine Rolle, obwohl auch die gramnegativen Bakterien zunehmend Multiresistenzen ausbilden (Brodt 2013). Die Befragung der ghanaischen Patienten ergab, dass 11 von ihnen (5,5\%) innerhalb der letzten vier Wochen Chloramphenicol eingenommen hatten. Fünf Patienten waren jünger als 8 Jahre. Die Beschwerden dieser Patienten gingen von Husten über Kopfschmerz bis hin zu Durchfall und Malaria. Keines dieser Symptome ist als primäre Indikation für eine Chloramphenicolanwendung anzusehen. Dieses Resultat ist ein Beispiel für den irrationalen Einsatz von Antibiotika in Ghana. Ursprünglich hatte Chloramphenicol eine gute Wirksamkeit gegen grampositive und gramnegative Bakterien sowie sporenlose Anaerobier. Galimand et al. fanden zwischen 1987 und 1996 mehrere high level Chloramphenicol-Resistenzen bei Neisseiria meningitidis, insbesondere in Vietnam. Die Stämme produzierten aktive Chloramphenicol-Acetyltransferase. Es wird vermutet, dass die genetische Information durch Gentransfer von Clostridium perfringens übertragen wurde. Die Gefahr dieser Entwicklung besteht darin, dass Chloramphenicol in vielen Ländern des Südens die Standardtherapie der Meningokokken-Meningitis ist (Galimand et al. 1997). Seit 2004 wurde Chloramphenicol zur Behandlung von Typhus in den nationalen Richtlinien durch Ciprofloxacin ersetzt (Gross et al. 2011). In den Untersuchungen von Gross et al. wurden 2009 Chloramphenicol-Resistenzen bei gramnegativen Bakterien mit bis zu 100,0\% nachgewiesen.

Die Stichprobenzahlen der hier bestimmten Erreger sind zu gering, um eine konkrete Resistenzrate für jeden Keim zu benennen. Fasst man jedoch die Enterobacteriaceae in eine Gruppe zusammen, ergibt sich eine Chloramphenicol-Resistenzrate bei den aus Abstrichen ghanaischer Probanden stammenden Enterobacteriaceae von 26,2\%, bei den in Abstrichen deutscher Probanden nachgewiesenen Enterobacteriaceae waren 16,7\% Chloramphenicolresistent. Dieses Ergebnis ist jedoch nicht statistisch signifikant ( $\mathrm{p}>0,1)$. Anders verhält es sich bei Staphylococcus aureus mit Chloramphenicol-Resistenzraten von 47,0\% in Ghana und 6,3\% in Deutschland (signifikanter Unterschied, $\mathrm{p}<$ 0,001). Die Koagulase-negativen Staphylokokken zeigten bei diesem Antibiotikum innerhalb der beiden Gruppen die größte Varianz: In Ghana waren 48,0\% der KNS resistent, in den deutschen Proben waren es 2,0\% $(\mathrm{p}<0,0001)$. 
Diese teilweise gravierenden Unterschiede lassen einen Zusammenhang zwischen Häufigkeit der Anwendung und Resistenzentwicklung vermuten. Jedoch spielen bei der Resistenzentwicklung auch andere Faktoren wie Dauer der Anwendung und Güte der Medikamente, aber auch Korrelation zwischen Wirkspektrum und Anwendungsgebiet eine Rolle (Harbarth et al. 2002, Kunze und Trenkmann 1989, Mills-Robertson et al. 2002, Schindler et al. 2003). Hierzu erschloss die Befragung der Probanden aus Ghana in einigen Fällen mangelhafte Aufklärung über die Präparate und deren Anwendung sowie unregelmäßige und kurzfristige Einnahme.

Einige Keime waren in so geringen Prozentsätzen vertreten, dass eine Auswertung der Resistenzlage nicht repräsentativ vorgenommen werden konnte.

MRSA im Vergleich Ghana - Deutschland

Staphylococcus aureus gehört zu den häufigsten fakultativ pathogenen Bakterienarten der Nasenflora. Sie können dem immungeschwächten Organismus gefährlich werden, daher kann eine Eradikation durchaus in einigen Fällen (zum Beispiel bei Patienten mit chronischen Lungenerkrankungen oder immunschwächenden Erkrankungen) sinnvoll sein (Lederer et al. 2007).

Jedoch ist eine MRSA-Besiedlung beim gesunden, nicht im Gesundheitswesen beschäftigten, Menschen keine Indikation zur Eradikation. Ein Großteil der gesunden Menschen ist mit Staphylococcus aureus besiedelt (von Eiff et al. 2001). Man kann daraus schlussfolgern, dass die Keime nicht schädlich für den Menschen sind, solange sie nur auf intakten Schleimhäuten gefunden werden. Kommt es jedoch durch Operationen oder Haut- und Schleimhautläsionen zum Eindringen des Erregers ins Gewebe, so kann S. aureus zur Infektion oder Bakteriämie und Sepsis führen. Es sind bei chronisch Kranken (z.B. HIV-infizierten Kindern) zudem höhere Raten der MRSA-Besiedlung zu verzeichnen als dies bei Gesunden der Fall ist (Cotton et al. 2008, von Eiff et al. 2001).

Das Gesamtvorkommen von S. aureus in dieser Studie war im Vergleich zwischen Ghana und Deutschland annähernd identisch, während MRSA in Ghana häufiger zu finden war.

Um eine signifikante Aussage treffen zu können ist die Anzahl der untersuchten Isolate zu gering. Es lässt sich jedoch eine Tendenz erkennen, die auch in der Literatur zu verzeichnen ist (Bell und Turnidge 2002). Dort wird die MRSA-Rate in Afrika mit Spitzenwerten von 41,5\% (Südafrika) der getesteten S. aureus-Isolate beziffert (Daschner und Schumpelick 
2002). In Deutschland liegt die MRSA-Rate bei etwa 20,3\% (Germap 2010). In Krankenhäusern wurden mangelnde Händehygiene und fehlende Isolationszimmer als Hauptrisiko für eine MRSA-Ausbreitung definiert. Bei Menschen außerhalb des Gesundheitsdienstes hat insbesondere die Massentierhaltung $\mathrm{zu}$ Infektionen und Kolonisationen in verschiedenen europäischen Ländern geführt (Cookson 2011).

Es erscheint gerade in den afrikanischen Ländern, die mit hohen HIV-Infektionsraten umgehen müssen, als unerlässlich, die Ausbreitung von multiresistenten Keimen mit allen Mitteln einzudämmen. Es gibt dazu verschiedene Ansätze; wichtig ist die Isolation besiedelter Patienten wie auch die strengere Infektionskontrolle durch ausgebildetes Personal (Coovadia et al. 1992, Cookson 2011, Marais et al. 2004, Paterson et al. 2004).

Auch für die lokale Eradikation von S. aureus-besiedelten Personen gibt es Ansätze: Uehara et al. konnte in eine Studie erfolgreich die nasale Besiedlung durch S. aureus durch die Implantation von Corynebakterien reduzieren (Uehara et al. 2000). Auch die lokale Antibiotikatherapie zur Eradikation, z.B. mit Clarithromycin/Mupirocin wird praktiziert, jedoch ebenfalls mit einem hohen Risiko der Resistenzentwicklung (Berg et al. 2004). Darüber hinaus gibt es den Ansatz von enteral zugeführten Probiotika, die ebenfalls die nasale Besiedlung mit fakultativ pathogenen Keimen reduzieren soll (Glück und Gebbers 2003).

Als erster, essenzieller Schritt sollte jedoch die weitere Aufklärung über eine adäquate Durchführung antibiotischer Behandlungen und die Ausweitung der prätherapeutischen Diagnostik (Keimbestimmung, Antibiogramme) besonders in den Ländern des Südens angesiedelt werden. Verständliche aktuelle Richtlinien für den Gebrauch von Antibiotika bei Menschen, aber auch in der Tierzucht müssen erstellt werden, und der „over-the-counter“Konsum sollte beendet werden (Benbachir et al. 2001, Bosu und Ofori-Adjei 1997a, Cookson 2011, Manie et al. 1999).

Pathogenität der in den Nasenabstrichen identifizierten Bakterien - die Nase als Reservoir

Als physiologische, apathogene Nasenflora werden z.B. Koagulase-negative Staphylokokken, Corynebakterien, Neisserien, und Bacillus spp. angesehen. Die Veränderung der Flora kann die sogenannte Kolonisationsresistenz vermindern und dadurch bakterielle Infektionen begünstigen (WHO 2000).

Die Nasenschleimhaut mit ihrer permanenten und transienten Flora kann somit als natürliches Reservoir von fakultativ pathogenen Bakterien angesehen werden, die z.B. bei 
Traumatisierung der Schleimhaut zu endogenen Infektionen führen kann. Eine der häufigsten Quellen für Bakteriämie, z.B. durch S. aureus - insbesondere MRSA - ist die anteriore Nase (Archer und Climo 2001, Daschner und Schumpelick 2002, Fujimori et al. 1996, von Eiff et al. 2001). Einen ähnlichen Effekt hat eine chronische Reizung der Nasenschleimhaut etwa durch industrielle Schadstoffe aus der Luft (Beck and Schmidt 1987, Hofmann 1990), passives Rauchen oder Allergene. Dieser Mechanismus führt vor allem bei Kindern zu einer ständigen Infektneigung, wenn die Pathogene nicht aus den Atemwegen entfernt werden (Fujimori et al. 1996, Ritter et al. 1990).

Es gibt zudem Studien, die nachgewiesen haben, dass in der Nase lokalisierte Bakterien höhere Resistenzraten aufweisen als Kommensalen an anderen Körperstellen (Ako-Nai et al. 1991).

Die Problematik der opportunistischen Infektionen ist gerade für viele afrikanische Länder ein großes Problem und eine Ursache zahlreicher Todesfälle vor allem bei Kindern. Fehlende Impfmöglichkeiten, Malaria- und HIV-Infektionen, aber auch Mangelernährung und geringe Hygiene sind begünstigende Faktoren für endogene Infektionen. Zahlreiche Kinder sterben jährlich an Infekten der Atemwege, die primär nicht tödlich sind und mit entsprechenden Ressourcen gut behandelbar wären (Black et al. 2010, WHO Child Mortality 2013).

Da die Abstriche der ghanaischen Patienten im Ambulanzbereich eines Krankenhauses vorgenommen wurden, waren folglich die meisten der Probanden zum Zeitpunkt der Entnahme krank bzw. hatten einen Grund, sich in medizinische Behandlung zu begeben. Ein knappes Viertel war schwanger. Etwa ein Drittel der Patienten kam mit unklaren Schmerzen und ca. 12,0\% litten unter Malaria. Alle diese zur ärztlichen Vorstellung führenden Zustände sind nicht primär in Zusammenhang mit einer Beeinflussung der nasalen Flora zu bringen, so dass bei weit über der Hälfte der Patienten kein Grund für die Vermutung besteht, vermehrt pathogene Keime zu finden.

Nur 11,0\% litten unter Husten und ca. 18,0\% kamen mit einem fieberhaften Infekt in die Poliklinik. Daher ist zumindest bei diesem Teil der ghanaischen Probanden auch in der Nase eine pathogene Bakterienbesiedlung möglich. Von den 22 Patienten mit Atemwegserkrankungen waren in der Tat $16(72,7 \%)$ mit fakultativ pathogenen Keimen besiedelt. Da diese Zahl jedoch unterhalb der Rate der pathogenen Besiedlung des Gesamtkollektivs (82,5\% aller getesteten Ghanaer hatten fakultativ pathogene Keime in der Nase) liegt, konnte eine mit Atemwegsinfektionen in Verbindung gebrachte veränderte Nasenbesiedlung nicht bestätigt werden. 


\section{Diskussion}

Insgesamt kann postuliert werden, dass diese Studie, trotz der Vielzahl der durch die Umstände der Datenerhebung entstandenen Einflussfaktoren, einen repräsentativen Einblick in die Keimbesiedlung im Vergleich zwischen Ghana und Deutschland bietet.

Wolf et al. 1999 stellten ebenfalls ausgeprägte Unterschiede in der Nasopharyngealflora von Kindern aus Brasilien, Angola und den Niederlanden fest: So waren in den Abstrichen der Probanden aus Brasilien in 50,0\%, aus Angola in 57,0\% und aus den Niederlanden nur in 4,0\% der Abstriche enterische Bakterien und gramnegative Non-Fermenter nachweisbar. Daraus wird eine mögliche Erklärung für die ansteigende Zahl der Pneumonien durch gramnegative Bakterien abgeleitet (Wolf et al. 1999). 


\section{Zusammenfassung}

In dieser Studie sollte untersucht werden, ob es signifikante Unterschiede in der nasalen Keimbesiedlung von Personen aus Deutschland und Ghana gibt und wie das Resistenzverhalten der jeweiligen Bakterien aussieht. Dazu wurden 200 Nasenabstriche in Ghana entnommen und 101 in Deutschland, von denen aber 17 steril blieben und aus der Gesamtauswertung herausfielen.

Die prägnantesten Unterschiede in der bakteriellen Besiedlung zeigten sich im Bereich der fakultativ pathogenen gramnegativen Stäbchen: Sowohl Enterobakterien als auch Pseudomonas/Stenotrophomonas und andere Non-Fermenter kamen statistisch signifikant häufiger in den Proben aus Ghana vor. Bei der Auswertung der apathogenen Residualflora waren lediglich coryneforme Bakterien und Neisserien in Ghana signifikant häufiger nachweisbar. Bei Staphylococcus aureus gab es keinen signifikanten Unterschied in der Verteilung, in den Proben aus Ghana wurden jedoch 6 MRSA gefunden, in den deutschen Proben keine. Als Ursache für die unterschiedliche Keimverteilung werden gesundheitlich- und ernährungsbedingte, aber auch hygienische Umstände vermutet. Im Bereich der Hygiene erscheint es möglich, mit einfachen Aufklärungskampagnen die hygienischen Standards (insbesondere der Körper- und Toilettenhygiene) zu verbessern und so eine Reduktion der Besiedlung mit Enterobakterien zu erreichen.

Bei den Antibiotikaresistenzen fiel vor allem die unterschiedliche Sensitivität gegenüber Chloramphenicol auf, das in Ghana zum Untersuchungszeitpunkt noch regelmäßig angewendet wurde. Die Bakterien aus den Abstrichen von Patienten aus Ghana, insbesondere die grampositiven, waren insgesamt deutlich häufiger resistent gegen Chloramphenicol.

Die Koagulase-negativen Staphylokokken der aus Deutschland stammenden Abstriche waren signifikant häufiger resistent gegen Ciprofloxacin, ein in Deutschland regelmäßig angewendetes Antibiotikum. Ein entscheidender Faktor für die unterschiedliche Antibiotikasensitivität scheint die Häufigkeit der Antibiotika-Anwendung zu sein.

Weltweit führt ein unreflektierter Umgang mit Antibiotika, mangelndes Wissen und Einsatz inadäquater Wirkstoffe zunehmend zur Resistenzentwicklung der Bakterien. Gezielte Schulungs- und Aufklärungskampagnen sowie ein überlegter Einsatz von Antibiotika könnten dieser Entwicklung entgegenwirken. 


\section{Literaturverzeichnis}

1 Ako-Nai AK, Ogunniyi AD, Lamikanra A, Torimiro SE (1991): The characterisation of clinical isolates of Staphylococcus aureus in Ile-Ife, Nigeria. J Med Microbiol $\underline{34(2)}, 109-112$

2 Alban S, Leininger MM, Reynolds CL: Multikulturelle Pflege. Urban und Fischer Verlag, München 2000

3 Anokbonggo WW, Ogwal-Okeng JW, Obua C, Aupont O, Ross-Degnan D (2004): Impact of decentralization on health services in Uganda: A look at facility utilization, prescribing and availability of essential drugs. East Afr Med J Suppl: S2-7

4 Archer GL, Climo MW (2001): Staphylococcus aureus bacteremia--consider the source. N Engl J Med 344(1), 55-56

5 Beck EG, Schmidt P (1987): Strategy of environmental medical research. Zentralbl Bakteriol Microbiol Hyg B 185(3), 201-210

6 Bell JM, Turnidge JD (2002): High prevalence of Oxacillin-resistant Stapylococcus aureus isolates from hospitalized patients in Asia-Pacific and South Africa: Results from SENTRY Antimicrobial Surveillance Program, 1998-1999. Antimicrob Agents Chemother $\underline{46(3)}, 879-881$

7 Benbachir M, Benredjeb S, Boye CS, Dosso M, Belabbes H, Kamoun A, Kaire O, Elmdaghri N (2001): Two-year surveillance of antibiotic resistance in Streptococcus pneumoniae in four African cities. Antimicrob Agents Chemother 45(2), 627-629

8 Berg HF, Tjhie JH, Scheffer GJ, Peeters MF, van Keulen PH, Kluytmans JA, Stobberingh EE (2004): Emergence and persistence of macrolide resistance in oropharyngeal flora and elimination of nasal carriage of Staphylococcus aureus after therapy with slow-release clarithromycin: a randomized, double-blind, placebocontrolled study. Antimicrob Agents Chemother 48(11), 4183-4188

9 Black RE, Cousens S, Johnson HL, Lawn JE, Rudan I, Bassani DG, Jha P, Campbell H, Fischer Walker C, Cibulskis R, Eisele T, Liu L, Mathers C (2010): Global, regional, and national causes of child mortality in 2008: a systematic analysis. Lancet $\underline{375(9730)}, 1969-1987$

10 Bonomo RA, Rossolini GM (2008): Importance of antibiotic resistance and resistance mechanisms. Foreword. Expert Rev Anti Infect Ther 6(5), 549-550

11 Bosu WK, Acquah S (1996): Susceptibility of urinary tract bacteria to antibiotics in Cape Coast, Ghana. East Afr Med J 73(7), 468-470

12 Bosu WK, Ofori-Adjei D (1997a): A 1-day survey of drug prescribing patterns in the District General Hospital of the Wassa West District of Ghana. Trop Doct 27(4), 222226 
13 Bosu WK, Ofori-Adjei D (1997b): Survey of antibiotic prescribing pattern in government health facilities of the Wassa west district of Ghana. East Afr Med J $\underline{74(3)}, 138-142$

14 Bosu WK, Ofori-Adjei D (2000): An audit of prescribing practices in health care facilities of the Wassa West district of Ghana. West Afr J Med 19(4), 298-303

15 Brink AJ, Cotton MF, Feldman C, Geffen L, Hendson W, Hockman MH, Maartens G, Madhi SA, Mutua-Mpungu M, Swingler GH (2004): Guideline for the management of upper respiratory tract infections. S Afr Med J 94(6 Pt 2), 475-483

16 Brodt HR: Antibiotika-Therapie: Klinik und Praxis der antiinfektiösen Behandlung. 12. Auflage; Schattauer Verlag, Stuttgart 2013

17 Charan J, Mulla S, Ryavanki S, Kantharia N (2012): New Delhi Metallo-beta lactamase-1 containing Enterobacteriaceae: Origin, Diagnosis, Treatment and Public health concern. Pan Afr Med J 11(22), PMCID: PMC3325060

18 Commey JO, Rodrigues OP, Akita FA, Newman M (1994): Bacterial meningitis in children in southern Ghana. East Afr Med J 71(2), 113-117

19 Cookson B (2011): The art of medicine. Five decades of MRSA:controversy and uncertainty continues. Lancet 378(9799), 1291-1292

20 Coovadia YM, Johnson AP, et al. (1992): Multiresistant Klebsiella pneumoniae in a neonatal nursery: the importance of maintenance of infection control policies and procedures in the prevention of outbreaks. J Hosp Infect 22, 197-205

21 Cotton MF, Wasserman E, Smit J, Whitelaw A, Zar HJ (2008): High incidence of antimicrobial resistant organisms including extended spectrum beta-lactamase producing Enterobacteriaceae and methicillin-resistant Staphylococcus aureus in nasopharyngeal and blood isolates of HIV-infected children from Cape Town, South Africa. BMC Infect Dis 8(40), ISSN 1471-2334

22 Daschner F, Schumpelick V (2002): MRSA als Herausforderung an die klinische Organisation. Chirurg 73(9), 924-929

23 De Souza C, Gbeassor M, Koumaglo K (1988): Sensibilite aux antibiotiques des souches de Staphylococcus aureus isolees a Lome. Med Trop 48(3), 243-247

24 Djie-Maletz A, Reither K, Danour S, Anyidoho L, Saad E, Danikuu F, Ziniel P, Weitzel T, Wagner J, Bienzle U, et al. (2008): High rate of resistance to locally used antibiotics among enteric bacteria from children in Northern Ghana. J Antimicrob Chemother 61(6), 1315-1318

25 Echave P, Bille J, Audet C, Talla I, Vaudaux B, Gehri M (2003): Percentage, bacterial etiology and antibiotic susceptibility of acute respiratory infection and pneumonia among children in rural Senegal. J Trop Paediatr $\underline{49(1)}$, 28-32 
26 Enweronu-Laryea CC, Newman MJ (2007): Changing pattern of bacterial isolates and antimicrobial susceptibility in neonatal infections in Korle Bu Teaching Hospital, Ghana. East Afr Med J 84(3), 136-140

27 Falagas ME, Grammatikos AP, Michalopoulos A (2008): Potential of old-generation antibiotics to address current need for new antibiotics. Expert Rev Anti Infect Ther $\underline{6(5)}, 593-600$

28 Felmingham D, Robbins MJ, Dencer C, Nathwani A, Gruneberg RN (1996): Antimicrobial susceptibility of community-acquired bacterial lower respiratory tract pathogens. J Antimicrob Chemother 38(4), 747-751

29 Fluckiger U, Widmer AF (1999): Epidemiology of methicillin-resistant Staphylococcus aureus. Chemotherapy 45(2), 121-134

30 Foster TJ (2004): The Staphylococcus aureus "superbug". J Clin Invest 114(12), 16931696

31 Fujimori I, Hisamatsu K, Kikushima K, Goto R, Murakami Y, Yamada T (1996): The nasopharyngeal bacterial flora in children with otitis media with effusion. Eur Arch Otorhinolaryngol 253(4-5), 260-263

32 Geyid A, Lemeneh Y (1991): The incidence of methicillin resistant S. aureus strains in clinical specimens in relation to their beta-lactamase producing and multiple-drug resistance properties in Addis Abeba. Ethiop Med J 29(4), 149-161

33 Glück U, Gebbers JO (2003): Ingested probiotics reduce nasal colonization with pathogenic bacteria (Staphylococcus aureus, Streptococcus pneumoniae, and betahemolytic streptococci). Am J Clin Nutr 77(2), 517-520

34 Groß U, Amuzu SK, de Ciman R, Kassimova I, Groß L, Rabsch W (2011): Bacteremia and antimicrobial drug resistance over time, Ghana. Emerg Infect Dis 17(10), 18791882

35 Hanssen AM, Kjeldsen G, Sollid JU (2004): Local variants of Staphylococcal cassette chromosome mec in sporadic methicillin-resistant Staphylococcus aureus and methicillin-resistant coagulase-negative Staphylococci: evidence of horizontal gene transfer? Antimicrob Agents Chemother 48(1), 285-296

36 Hanssen AM, Fossum A, Mikalsen J, Halvorsen DS, Bukholm G, Sollid JU (2005): Dissemination of community-acquired methicillin-resistant Staphylococcus aureus clones in northern Norway: sequence types 8 and 80 predominate. J Clin Microbiol 43(5), 2118-2124

37 Harbarth S, Albrich W, Brun-Buisson C (2002): Outpatient antibiotic use and prevalence of antibiotic-resistant pneumococci in France and Germany: a sociocultural perspective. Emerg Infect Dis $\underline{\text { 8(12) }}$, 1460-1467

38 Hofmann H (1990): Überhöhte Morbidität bei Krippenkindern - Bestandsaufnahme einer Industrieregion. Pädiatr Grenzgeb 29(6), 495-501 
39 Itah AY, Ben AE (2004): Incidence of enteric bacteria and Staphylococcus aureus in day care centers in Akwa Ibom State, Nigeria. Southeast Asian J Trop Med Public Health $\underline{35(1)}, 202-209$

40 Kesah C, Ben Redjeb S, Odugbemi TO, Boye CS, Dosso M, Ndinya Achola JO, Koulla-Shiro S, Benbachir M, Rahal K, Borg M (2003): Prevalence of methicillinresistant Staphylococcus aureus in eight African hospitals and Malta. Clin Microbiol Infect $\underline{9(2)}, 153-156$

41 Kumarasamy KK, Toleman MA, Walsh TR, Bagaria J, Butt F, Balakrishnan R, Chaudhary U, Doumith M, Giske CG; Irfan S, et al.(2010): Emergence of a new antibiotic resistance mechanism in India, Pakistan, and the UK: a molecular, biological, and epidemiological study. Lancet Infect Dis 10(9), 597-602

42 Kunze M, Trenkmann B (1989): Die Wirksamkeit der antimikrobiellen Chemotherapie bei Patienten mit einer akuten Infektion der oberen Atemwege. Z Ärztl Fortbild $\underline{\text { 83(1) }}$, 29-31

43 Lamikanra A, Ako-Nai AK, Ola O (1989): Incidence of multiple antibiotic resistances in organisms isolated from cases of infantile diarrhoea in a Nigerian oral rehydration therapy clinic. Ann Trop Paediatr 9(4), 256-260

44 Lederer SR, Riedelsdorf G, Schiffl H (2007): Nasal carriage of meticillin resistant Staphylococcus aureus: the prevalence, patients at risk and the effect of elimination on outcomes among outclinic haemodialysis patients. Eur J Med Res 12(7), 284-288

45 Liu Z, Li W, Wang J, Pan J, Sun S, Yu Y, Zhao B, Ma Y, Zhang T, Qi J, Liu G, Lu F (2013): Identification and characterization of the first Escherichia coli strain carrying NDM-1 gene in China. PLoS One 8(6), e66666. doi: 10.1371/journal.pone.0066666. Print 2013.

46 Mackie EJ, Shears P, Frimpong E, Mustafa-Kutana SN (1992): A study of bacterial meningitis in Kumasi, Ghana. Ann Trop Paediatr 12(2), 143-148

47 Manie T, Brozel VS, Veith WJ, Gouws PA (1999): Antimicrobial resistance of bacterial flora associated with bovine products in South Africa. J Food Prot $\underline{62(6)}$, 615-618

48 Marais E, de Jong G, Ferraz V, Maloba B, Duse AG (2004): Interhospital transfer of pan-resistant Acinetobacter strains in Johannesburg, South Africa. Am J Infect Control $\underline{32(5)}, 278-281$

49 Mettler J, Simcock M, Sendi P, Widmer AF, Bingisser R, Battegay M, Fluckiger U, Bassetti S (2007): Empirical use of antibiotics and adjustment of empirical antibiotic therapies in a university hospital: a prospective observational study. BMC Infect Dis 7(21), doi:10.1186/1471-2334-7-21 
50 Mills-Robertson F, Addy ME, Mensah P, Crupper SS (2002): Molecular characterization of antibiotic resistance in clinical Salmonella typhi isolated in Ghana. FEMS Microbiol Lett 215(2), 249-253

51 Ndip RN, Obi MC, Obi CL, Nwawolo C, Igumbor EO, Obi AA (1995): Antibiogram of bacterial isolates from cases of otitis media and lower respiratory tract infections. Afr J Med Sci 24(4), 353-357

52 Nyembue DT, Tshiswaka J-M, Sabue MJ, Muyunga CK (2003): Bacteriology of chronic suppurative otitis media in Congolese children. Acta Otorhinolaryngol Belg $\underline{57(3)}, 205-208$

53 Ohene A (1997): Bacterial pathogens and their antimicrobial susceptibility in Kumasi, Ghana. East Arf Med J 74(7), 450-455

54 Okolo MI (1986): Bacterial drug resistance in meat animals: A Review. Int J Zoon $\underline{13(3)}, 143-152$

55 Paterson DL, Ko WC, Von Gottberg A, Mohapatra S, Casellas JM, Goossens H, Mulazimoglu L, Trenholme G, Klugman KP, Bonomo RA (2004): International prospective study of Klebsiella pneumoniae bacteremia: implications of extendedspectrum beta-lactamase production in nosocomial Infections. Ann Intern Med 140(1), 26-32

56 Petit PL, Haarlem JV, Poelman M, Haverkamp MC, Wamola IA (1995): Bacteraemia in patients presenting with fever. East Afr Med J $\underline{72(2)}$, 116-120

57 Ritter E, Grimmer I, Adamczyk G, Schmidt G (1990): Die mikrobielle Besiedlung der oberen Atemwege von Krippenkindern in Abhängigkeit vom akuten Morbiditätsgeschehen. Z gesamte Hyg 36(11), 617-620

58 Schindler C, Krappweis J, Morgenstern I, Kirch W (2003): Prescriptions of systemic antibiotics for children in Germany aged between 0 and 6 years. Pharmacoepidemiol Drug Saf 12(2), 113-120

59 Shakil S, Azhar EI, Tabrez S, Kamal MA, Jabir NR, Abuzenadah AM, Damanhouri GA, Alam Q (2011): New Delhi metallo- $\beta$-lactamase (NDM-1): an update. J Chemother 23(5), 263-265

60 Shanahan PM, Wylie BA, Adrian PV, Koornhof HJ, Thomson CJ , Amyes SG (1993): The prevalence of antimicrobial resistance in human faecal flora in South Africa. Epidemiol Infect 111(2), 221-228

61 Shanahan PM, Thomson CJ, Amyes SG (1995): Beta-lactam resistance in normal faecal flora from South Africa. Epidemiol Infect 115(2), 243-253

62 Uehara Y, Nakama H, Agematsu K, Uchida M, Kawakami Y, Abdul Fattah AS, Maruchi N (2000): Bacterial interference among nasal inhabitants: eradication of Staphylococcus aureus from nasal cavities by artificial implantation of Corynebacterium sp. J Hosp Infect 44(2), 127-133 
63 von Eiff C, Becker K, Machka K, Stammer H, Peters G (2001): Nasal carriage as a source of Staphylococcus aureus bacteremia. N Engl J Med 344(1), 11-16

64 Wanyenya I, Muyanja C, Nasinyama GW (2004): Kitchen practices used in handling broiler chickens and survival of Campylobacter spp. On cutting surfaces in Kampala, Uganda. J Food Prot 67(9), 1957-1960

65 Wolf B, Gama A, Rey L, Fonseca W, Roord J, Fleer A, Verhoef J (1999): Striking differences in the nasopharyngeal flora of healthy Angolan, Brazilian and Dutch children less than 5 years old. Ann Trop Paediatr 19(3), 287-292

\section{Internetquellen}

$66 \quad$ BFR 2012

http//:www.bfr.bund.de:Stellungnahme Nr. 002/2012des BfR vom 5.12.2011

67 Germap 2010

http://www.bvl.bund.de/SharedDocs/Downloads/08_PresseInfothek/Germap_2010.

pdf ?_blob=publicationFile\&v $=2$

68 Statistisches Bundesamt 2013

https://www.destatis.de/DE/Publikationen/Thematisch/Gesundheit/Gesundheitsausgab en/AusgabenGesundheitPDF_2120711.pdf?_blob=publicationFile

69 WHO Infectious Disease 2000

http://www.who.int/infectious-disease-report/2000/

70 WHO GLAAS 2008

http://www.who.int/water_sanitation_health/glaas/2008_pilot/glaas_2008_pilot_finale report.pdf

71 WHO Statistical Fact Sheet 2010

http://www.afro.who.int/en/ghana/country-health-profile.html

72 WHO Child Survival 2012

http://www.afro.who.int/en/clusters-a-programmes/frh/child-and-adolescenthealth.html

73 WHO 2013a

http://www.who.int/gho/countries/gha/country_profiles/en/index.html

74 WHO 2013b

http://www.who.int/gho/countries/deu.pdf

$75 \quad$ WHO Child Mortality 2013

http://www.childinfo.org/files/Child_Mortality_Report_2013.pdf 


\section{Lebenslauf}

Mein Name ist Hannah Sophia Seeba, ich wohne in der Kolpingstrasse 8, in 28195 Bremen. Ich wurde am 15.08.1977 in Bremen, als erstes Kind von Wilfried Seeba und Ulrike Seeba, geb. Bartke geboren.

Am 14.03.1997 wurde meine Tochter Mia Lara geboren. Ich habe keine

Religionszugehörigkeit.

1983 erfolgte meine Einschulung in die Grundschule Neerstedt, Niedersachsen.

Durch den Umzug nach Bremen fand ein Schulwechsel in die Bürgermeister-Smidt-

Grundschule, 2.-4. Klasse (1984-1987) statt.

1987- 1989 folgte der Besuch der Orientierungsstufe an der Brokstraße in Bremen.

Von 1989- 1993 besuchte ich den gymnasialen Zweig der Sekundarstufe I, Schule an der

Schaumburgerstrasse in Bremen.

1993-1994 wurde die deutsche Schullaufbahn durch einen Schüleraustausch mit den USA

unterbrochen: Ich besuchte die Robert E. Lee High School in Midland, Texas.

Im Sommer 1994 erlangte ich das amerikanische High School Diploma.

1994-1996 folgte der Besuch der gymnasialen Oberstufe der Schule an der Hamburgerstraße

in Bremen. Ich belegte die Leistungskurse Englisch und Spanisch und erlangte das Abitur im

Juni 1996.

Ich begann das Medizinstudium an der Georg-August-Universität in Göttingen im Sommersemester 1998.

2000 nahm ich erfolgreich an der Ärztlichen Vorprüfung teil.

2001 bestand ich den Ersten Abschnitt der Ärztlichen Prüfung.

2004 absolvierte ich den Zweiten Abschnitt der Ärztlichen Prüfung.

2004-2005 trat ich das Praktische Jahr in drei verschiedenen Bremer Kliniken an:

Das 1. Tertial absolvierte ich in der Inneren Medizin im St.-Joseph-Stift. Das 2. Tertial

erfolgte in der Pädiatrie im Klinikum Links der Weser und das 3. Tertial in der

Kinderchirurgie im Klinikum Bremen-Mitte.

20.04.2005 bestand ich das Dritte Staatsexamen im St.-Joseph-Stift in Bremen.

06/06-03/10 begann ich meine klinische Tätigkeit mit Facharztweiterbildung in der Pädiatrie des Klinikums Links der Weser in Bremen.

04/10-11/11 folgte die Facharztweiterbildung in der Kinderklinik Delmenhorst.

Seit 10/2013 bis heute bin ich als Weiterbildungsassistent in der Kinderarztpraxis Dr. Theek in Bassum angestellt.

Seit 01/06 bin ich außerdem als freie Mitarbeiterin der Bremer Pharmacovigilance Service $\mathrm{GmbH}$ tätig. Meine Zuständigkeiten beziehen sich auf Literaturrecherche, Telefonberatung, Gutachtenerstellung und PSURs. Ich bin Pharmakovigilanzbeauftrage und QPPV in verschiedenen Bereichen. 


\section{Danksagung}

Ich bedanke mich bei meinem Doktorvater Uwe Groß für viel Geduld und gute Beratung bei der Durchführung und dem Verfassen der Dissertation. Ebenso danke ich meinem vertretenden Doktorvater Gustl Stich. Ich danke allen Helfern und freiwilligen Probanden, die diese Arbeit möglich gemacht haben. 